\title{
Long Non-coding RNAs in Hepatitis C Virus-Infected Cells
}

\author{
Marina Barriocanal and Puri Fortes* \\ Department of Gene Therapy and Hepatology, Navarra Institute for Health Research (IdiSNA), Centro de Investigación \\ Médica Aplicada, University of Navarra, Pamplona, Spain
}

Hepatitis $\mathrm{C}$ virus ( $\mathrm{HCV}$ ) often leads to a chronic infection in the liver that may progress to steatosis, fibrosis, cirrhosis, and hepatocellular carcinoma (HCC). Several viral and cellular factors are required for a productive infection and for the development of liver disease. Some of these are long non-coding RNAs (IncRNAs) deregulated in infected cells. After HCV infection, the sequence and the structure of the viral RNA genome are sensed to activate interferon (IFN) synthesis and signaling pathways. These antiviral pathways regulate transcription of several cellular IncRNAs. Some of these are also deregulated in response to viral replication. Certain viral proteins and/or viral replication can activate transcription factors such as MYC, SP1, NRF2, or HIF1 $\alpha$ that modulate

OPEN ACCESS

Edited by:

Encarna Martinez-Salas, Centro de Biología Molecular Severo

Ochoa (CSIC), Spain

Reviewed by:

Juan-Carlos Saiz,

Instituto Nacional de Investigación y

Tecnología Agraria y

Alimentaria (INIA), Spain

David Piñeiro,

MRC Toxicology Unit (MRC),

United Kingdom

${ }^{*}$ Correspondence:

Puri Fortes

pfortes@unav.es

Specialty section:

This article was submitted to

Virology,

a section of the journal

Frontiers in Microbiology

Received: 29 June 2017 Accepted: 06 September 2017 Published: 28 September 2017

Citation:

Barriocanal M and Fortes $P$ (2017) Long Non-coding RNAs in Hepatitis C

Virus-Infected Cells.

Front. Microbiol. 8:1833.

doi: 10.3389/fmicb.2017.01833 the expression of additional cellular IncRNAs. Interestingly, several IncRNAs deregulated in HCV-infected cells described so far play proviral or antiviral functions by acting as positive or negative regulators of the IFN system, while others help in the development of liver cirrhosis and HCC. The study of the structure and mechanism of action of these IncRNAs may aid in the development of novel strategies to treat infectious and immune pathologies and liver diseases such as cirrhosis and HCC.

Keywords: IncRNAs, HCV, proviral, antiviral, IFN response, liver cirrhosis, fibrosis, HCC

\section{HEPATITIS C VIRUS (HCV) INFECTION}

Hepatitis $\mathrm{C}$ virus is a hepatotropic virus member of the Flaviviridae family discovered almost 30 years ago (Choo et al., 1989, 1991). HCV infection affects $1.6 \%$ of the world's population (@115 million people) with a prevalence of $0.1-23 \%$ depending on the region (Gower et al., 2014; Daw et al., 2016). Asia has the highest prevalence, with $60 \%$ of the HCV-infected people. Out of the six major genotypes described for $\mathrm{HCV}$, the most common is genotype 1, which is responsible for $46 \%$ of all infections, followed by genotypes 3, 2, 4, and 6. HCV infection is mainly caused by iatrogenic transmission in low- and middle-income countries, and by risky sexual practices and sharing needles while tattooing or injecting drugs in developed countries (Lanini et al., 2016). After HCV entry, the virus produces an acute infection which spontaneously resolves in $15-50 \%$ of cases within the first $12-16$ weeks, but which may become chronic in $55-85 \%$ of the cases (Ghany et al., 2009; AASLD/IDSA HCV Guidance Panel, 2015) (Figure 1). In many cases, the infection remains undiagnosed for many years, as chronic infection is frequently asymptomatic. The infection causes a liver injury that may progress to liver steatosis, fibrosis, cirrhosis and eventually hepatocellular carcinoma (HCC) (Carnero and Fortes, 2016; Miao et al., 2017) (Figure 1). Therefore, it is important to detect chronic HCV infection before the development of liver disease. Detection methods include identification of HCV RNA by PCR and HCV proteins by ELISA (Chevaliez and Pawlotsky, 2008; Ghany et al., 2009; AASLD/IDSA HCV Guidance Panel, 2015). There is 
no vaccine for prevention of $\mathrm{HCV}$ infection but direct antivirals have recently been developed that have attained sustained virological response rates higher than 90\% (Poordad and Khungar, 2011; Sarrazin et al., 2012; Sheridan et al., 2013; Bhamidimarri et al., 2017; Cento et al., 2017). However, given the prevalence of the infection and the high mutation rate of $\mathrm{HCV}$, which helps the virus to generate escape mutants resistant to the inhibitors, a strict epidemiological vigilance and a dedicated scientific research into $\mathrm{HCV}$-infection should not stop (Perales et al., 2015; Kan et al., 2017; Raj et al., 2017; Wyles et al., 2017). Effective vaccines against $\mathrm{HCV}$ will be required before the goal of a complete cure for HCV can be achieved.

\section{The Viral Particle}

Hepatitis C virus is a small (40-80 $\mathrm{nm}$ in size), enveloped virus that contains the viral genome bound to the core protein (Gastaminza et al., 2010; Catanese et al., 2013). The viral genome is a single-stranded RNA molecule of 9.6 kilobases and positive polarity (Lemon et al., 2007). The genome serves as messenger RNA and consists of a long open reading frame (ORF) flanked by highly structured $3^{\prime}$ and $5^{\prime}$ un-translated regions (UTRs), which are required for viral translation, replication and encapsidation. Interestingly, the $3^{\prime}$ and $5^{\prime}$ ends of $\mathrm{HCV}$ interact with each other (Romero-Lopez and Berzal-Herranz, 2009).

The $5^{\prime}$ UTR includes an internal ribosome entry site (IRES) that allows cap-independent translation of a single polyprotein (Sagan et al., 2015; Adams et al., 2017). The polyprotein is approximately 3000 amino acids in length and is co- and posttranslationally cleaved by viral and cellular proteases to produce all mature viral proteins: three structural proteins (core, E1, and E2) and seven non-structural proteins (p7, NS2, NS3, NS4A, NS4B, NS5A, and NS5B). Importantly, HCV proteins are characterized by their multi-functionality (Moradpour and Penin, 2013). The core protein is the main component of the HCV nucleocapsid and promotes nucleocapsid assembly (Boulant et al., 2006). The envelope of the viral particle contains the viral E1 and E2 glycoproteins, required for cell attachment and entry and for the assembly of the infectious HCV particle. P7 participates in HCV assembly and release (Moradpour and Penin, 2013; Atoom et al., 2014). NS2 autoprotease is required for the cleavage of NS2/NS3 and participates in virus assembly (Schregel et al., 2009; Jirasko et al., 2010). The replicase complex is formed by NS3, NS4A, NS4B, NS5A, and NS5B. NS3 is another viral protease and helicase. As a protease, NS3 processes non-structural proteins and cleaves some host factors involved in the antiviral response (Moradpour and Penin, 2013). As a helicase, NS3 is crucial for HCV RNA unwinding and replication and for viral particle assembly. NS4A helps binding of NS3 to the endoplasmic reticulum (ER), and increases NS3 activity. NS4B participates in viral assembly and is a key protein for the formation of the membranous web (MW) required for replication (Han et al., 2013). NS5A binds several proteins, the viral RNA and the membranes to participate in MW formation, virus replication and assembly and to block the antiviral response (Moradpour and Penin, 2013; Schoggins and Rice, 2013). Finally, NS5B is the RNA-dependent RNA polymerase essential for viral replication and assembly (Lohmann, 2013). Similar to other RNA polymerases, NS5B lacks proofreading activity. Viral progeny is a collection of viruses with mutated viral genomes known as quasispecies with a high capacity to escape the immune host system (Marascio et al., 2014).

\section{The Viral Cycle}

Hepatitis $\mathrm{C}$ virus viral particles circulate in the blood stream as lipoviroparticles (LVPs), attached to lipids and apolipoproteins (Apo) from the host (Grassi et al., 2016). This shell facilitates the infection of hepatocytes and may aid in viral escape from neutralizing antibodies. HCV entry into the hepatocytes is a highly regulated multi-step process that involves various cellular proteins. Once the virus is in the liver, at the space of Disse, it is captured by heparan sulfate proteoglycan receptors present in the basolateral membrane of the hepatocytes (Xu et al., 2015). There, LVPs are sequentially hydrolysed, the associated $A p o B$ is uncovered, and $A p o B$ exposure enables low-density lipid receptor (LDLR) binding to the LVPs. Then, these LVPs interact with scavenger receptor class B type I and CD81 (Chang et al., 2017), which allows migration of the particle to tight junctions, binding to claudin 1 (CLDN1) and occludin (OCLN) and internalization by endocytosis. After uncoating driven by the acidification of the endosome, the viral genome is released into the cytosol (Grassi et al., 2016; Miao et al., 2017).

Once the HCV genome is in the cytoplasm, viral replication takes place in the MW, a specialized structure formed by doublemembrane vesicles originating from the ER (Grassi et al., 2016). NS5A binds the HCV RNA and the viral RNA polymerase NS5B is in charge of replication. First, the positive-stranded RNA serves as template for the production of intermediate negativestranded RNAs. Then, the negative-stranded RNAs are copied into new positive-strand RNA viral genomes, which can be used for translation, replication, or packaging (Manns et al., 2017).

Hepatitis $C$ virus viral particle assembly occurs in the ER close to membrane-bound lipid droplets (LDs). NS5A binds the $3^{\prime}$ UTR of positive-stranded HCV RNAs and transfers the genomes from the replication complexes in the MW to the core proteins bound to the ER (Targett-Adams et al., 2010; Shi G. et al., 2016). Then, the nucleocapsids acquire their envelope, most probably, after budding into the ER. The new HCV virions adhere to nascent VLDL or LDL particles and form the LVPs that are transported to the Golgi for virus release (Syed et al., 2017). Therefore, a proper functionality of the lipid secretion pathway and a proper synthesis of VLDLs is essential for HCV release (Bassendine et al., 2013). HCV can be also transmitted directly from cell to cell, escaping the inhibitory action of neutralizing antibodies (Timpe et al., 2007; Brimacombe et al., 2011).

\section{HCV Host Factors}

Hepatitis $\mathrm{C}$ virus draws on multiple host cell factors for entry, replication, assembly, and release. As mentioned previously, key factors in the HCV cycle are: (i) host lipoproteins such as ApoE, ApoA, ApoB, or MTP that attach to HCV nucleocapsid and are required for entry (Chang et al., 2007; Huang et al., 2007; Mancone et al., 2012; Fukuhara et al., 2015); (ii) several hepatocyte receptors including CLDN1 and OCLN (Li Q. 


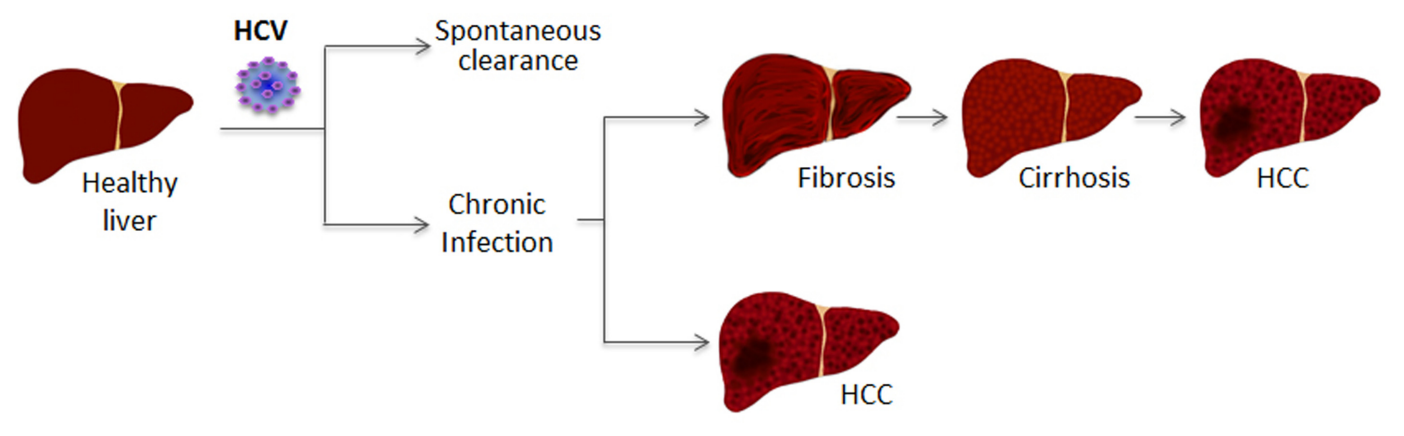

FIGURE 1 | Schematic of liver disease in HCV-infected patients.

et al., 2016); (iii) host factors required for MW formation, such as cyclophilin A or kinases like phosphatidylinositol-4kinase III alpha (PI4KIIIalpha) (Delang et al., 2012; Rosnoblet et al., 2012; Ross-Thriepland et al., 2013; Colpitts et al., 2015); (iv) cellular proteins that attach to the IRES and allow translation, like DDX5 and PARP1 (Ríos-Marco et al., 2016).

All of these are protein factors. However, efficient $\mathrm{HCV}$ infection also requires the expression of cellular micro and long non-coding RNAs (miRNAs and lncRNAs). The latter are the focus of this review and deserve a special chapter. In fact, upon HCV infection, the expression of many host miRNAs and lncRNAs is altered (Singaravelu et al., 2014b; Carnero and Fortes, 2016). Surprisingly, the miRNA miR-122 is one of the most limiting factors for HCV viability and development of HCV-associated HCC (Jopling et al., 2005; Kutay et al., 2006). miR122 is a liver-specific microRNA whose levels are upregulated by HCV. miR122 binds two conserved regions located at the $5^{\prime}$ end of the viral genome (Adams et al., 2017). Binding protects viral RNA from degradation by exonucleases, enhances HCV RNA replication, stimulates IRES-mediated translation and hides the $5^{\prime}$ end of the HCV genome from cellular sensors that activate the antiviral response (Henke et al., 2008; Shimakami et al., 2012; Li Y. et al., 2013; Sedano and Sarnow, 2014). This results in increased levels of viral RNA and viral proteins. It is not surprising that HCV RNA levels can be reduced in infected patients with a drug that blocks miR122 (Janssen et al., 2013). Remarkably, sequestration of cellular miR-122 by the viral genome results in increased levels of miR-122-targets and increased oncogenic potential of HCV (Israelow et al., 2014; Luna et al., 2015). Finally, it has been recently reported that miR122 also binds the NS5B coding region and the $3^{\prime}$ UTR, which is essential for HCV replication (Gerresheim et al., 2017). Other miRNAs altered upon HCV infection include miR199a-3p, let7-b or miR-181c, which inhibits replication by binding to E1 and NS5A sequences. miR185-5p and miR-27 are induced by core protein and control genes involved in lipid metabolism (Murakami et al., 2011; Cheng et al., 2012; Shirasaki et al., 2013; Singaravelu et al., 2014a; Li M. et al., 2015; Mukherjee et al., 2015). miR-208b and miR-499a-5p are induced by HCV and target a polymorphic region of interferon lambda (IFNL3) in the $3^{\prime}$ UTR in charge of controlling IFNL3 mRNA stability, decreasing the antiviral response against $\mathrm{HCV}$ infection (McFarland et al., 2013).

\section{THE ANTIVIRAL RESPONSE AGAINST HCV}

\section{Interferon Synthesis Pathway}

The cell has several mechanisms to recognize and fight against exogenous pathogens. Viruses produce pathogen-associated molecular patterns (PAMPs) that can be recognized by PAMP recognition receptors (PRRs). These PRRs are located on the cell surface or in intracellular compartments as endosomes, and identify viral RNA structures not present in the host cell by discriminating between viral RNA and RNA from the host. Tolllike receptors (TLRs) are able to recognize viral nucleic acids both in and out of the cell, while retinoic acid-inducible gene I (RIG-I) and melanoma differentiation-associated gene 5 (MDA5) sense intracellular viral ssRNA or dsRNA, according to the $5^{\prime}$ end structure and length, respectively (Scheel and Rice, 2013) (Figure 2). In the case of the HCV genome, the pU/UC tract located in the $3^{\prime}$ UTR is sensed by RIG-I in the cytoplasm of the cell soon after the virus has released its genome (Saito et al., 2008). Further, RIG-I and TLR3 can also sense dsRNA produced by viral replication (Binder et al., 2011; Dabo and Meurs, 2012; Li et al., 2012). RIG-I is auto inhibited by its regulatory domain, and upon sensing viral RNA, RIG-I undergoes conformation changes and ubiquitination by E3 ligase TRIM25 that lead to its dimerization and activation (Gack et al., 2007; Oshiumi et al., 2013b). Then, RIG-I associates with mitochondrial antiviral signaling protein (MAVS) via CARD-CARD (caspase activation and recruitment domains) interactions and this recruits TNF receptor associated factors (TRAFs) (Liu et al., 2012). On one hand, MAVS can activate TBK1/IKKE kinase (Hemmi et al., 2004). Then, interferon regulatory factors (IRFs) 3 and 7 are phosphorylated by IKK $\varepsilon$ and activated. On the other hand, MAVS activates nuclear factor $\kappa \mathrm{B}(\mathrm{NF}-\kappa \mathrm{B})$ through $\mathrm{IKK} \alpha / \mathrm{IKK} \beta / \mathrm{IKK} \gamma$ (Sharma et al., 2003; Thompson et al., 2011; Sun et al., 2015; Yang and Zhu, 2015). IRFs induce a first wave of interferon (IFN)-stimulated genes (ISG), NF- $\kappa \mathrm{B}$ induces inflammatory cytokines and, together, they activate type I IFN synthesis and secretion. 


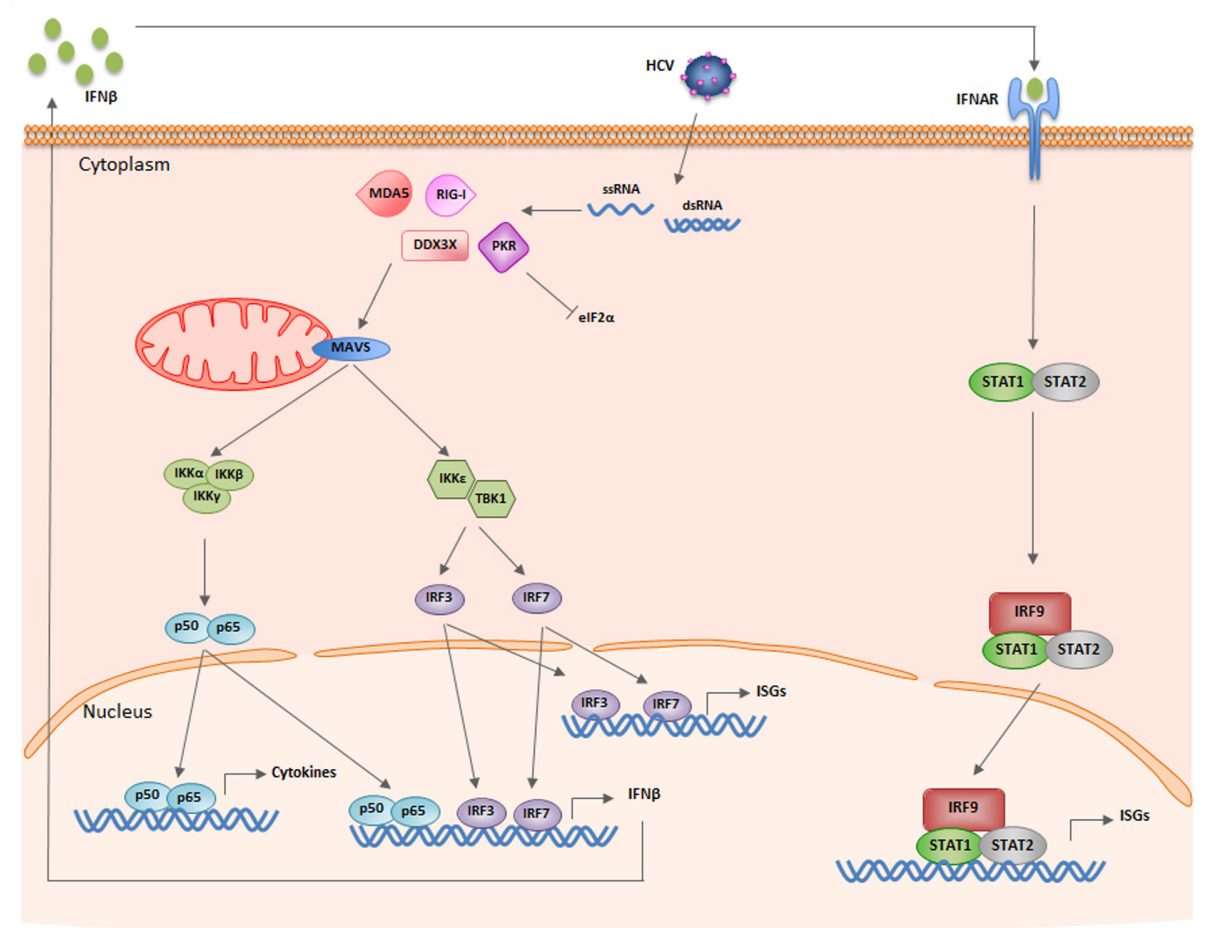

FIGURE 2 | Schematic of the IFN synthesis and signaling pathways induced by HCV infection. See text for details.

While this is the major IFN synthesis pathway, the HCV genome can also be sensed by non-canonical receptors such as protein kinase $\mathrm{R}$ (PKR) and DEAD box RNA helicase 3 (DDX3X) (Figure 2). PKR is a cytoplasm protein that binds the dsRNA IRES located at the $5^{\prime}$ UTR of the viral genome in a sequence-independent manner. PKR activation after dsRNA binding triggers interaction of PKR with MAVS, MAVS activation and transcription of ISGs (Dabo and Meurs, 2012). Further, active PKR phosphorylates eukaryotic translation initiation factor eIF2 $\alpha$ and impairs translation (Garaigorta and Chisari, 2009) (see below). DDX $3 X$ interacts with the $3^{\prime}$ UTR region of HCV and activates IKK $\alpha$. Unexpectedly, PKR and DDX3X are cellular sensors that favor HCV replication (Ariumi et al., 2007; Garaigorta and Chisari, 2009; Li Q. et al., 2013) (see below).

Professional bystander plasmacytoid dendritic cells (pDCs) can also secrete type I and type III IFNs after contacting HCV-infected cells (Stone et al., 2013). Infected cells release exosomes containing HCV-RNA that are sensed by the TLR7 receptor of the pDCs (Takahashi et al., 2010; Dreux et al., 2012; Nakai et al., 2015). Interestingly, pDCs respond to viral RNA even though they are not infected by HCV and they do not allow viral replication.

\section{IFN Signaling Pathway}

IFN $\alpha$ receptors (IFNAR), present on the surface of all cell types, bind to type I IFN (IFN $\alpha$ s, IFN $\beta$, and others) (Figure 2). Less promiscuous are IFN $\lambda$ receptors (IFNLR), which bind type III IFN or IFN $\lambda$ and have a strong influence on HCV replication
(Ge et al., 2009; Thomas et al., 2009; Boisvert and Shoukry, 2016). IFN receptor binding to infected and non-infected neighboring cells activates the Janus kinase-signal transducer and activator of transcription (JAK-STAT) pathway. JAK and Tyk2 kinases phosphorylate STAT molecules, STAT1 dimerizes with STAT2 and the heterodimer binds IRF9 to form the IFN-stimulated gene factor 3 (ISGF3). ISGF3 is translocated to the nucleus where it binds the IFN-stimulated response elements (ISREs) present in the ISG promoters to induce their transcription (Hertzog and Williams, 2013; Ivashkiv and Donlin, 2014; Schneider et al., 2014).

\section{Production of ISGs Affecting HCV Infection}

ISGs can be divided into three groups according to their function: (i) to increase the antiviral response; (ii) to inhibit viral replication and (iii) to help cells return to homeostasis. PKR, OAS or RNaseL, MxA, STAT1, STAT2, IRF1, 3, 7, and 9 are ISGs that belong to the first group. They function as positive regulators to reinforce pathogen detection, IFN synthesis and/or signaling and increase ISG expression. Oligoadenylate synthetase (OAS) recognizes PAMPs and activates latent endoribonuclease (RNase L) that cleaves viral and cellular ssRNAs reinforcing the antiviral response and providing new PAMPs (Schneider et al., 2014). Myxovirus resistance-A (MxA) stimulates the production of IFN $\alpha$ and IFN $\beta$ and enhances the JAK/STAT pathway (Shi et al., 2017). IRF1 is a transcription factor that binds ISRE-like sequences present in the promoter of several ISGs and induces 
ISG transcription after the first wave of IFN response (Schoggins et al., 2011).

Other ISGs affect several steps of the HCV life cycle: viral entry or uncoating, viral RNA replication, translation and stability or viral release (Schneider et al., 2014). IFITM proteins (IFN-induced transmembrane proteins) block viral entry by interacting with the CD81 receptor (IFITM1) or by capturing the virions at the endosomes for their degradation (IFITM2 and IFITM3) (Perreira et al., 2013; Narayana et al., 2015). IFIT proteins (IFN-induced proteins with tetratricopeptide repeats) inhibit virus replication and protein translation by affecting eIF3 (Zhou et al., 2013). TRIM proteins (tripartite-motif-containing proteins) affect infection of several viruses at different steps. TRIM5 $\alpha$ binds viral capsids to accelerate viral disassembly while TRIM22 inhibits viral transcription and regulation (Hattlmann et al., 2012; Schneider et al., 2014). TRIM22 ubiquitinates NS5A viral protein, interrupting replication in $\mathrm{HCV}$-infected cells (Yang et al., 2016). Viperin/RSAD binds to NS5A to affect virus replication and assembly (Helbig et al., 2005, 2011). Tetherin/BST2 affects HCV release and assembly. Tetherin is known to anchor $\mathrm{HIV}-1$ virions to the plasma membrane, blocking the release of the viral particle (Perez-Caballero et al., 2009). In HCV-infected cells the effect of viperin is milder than in HIV-1 (Dafa-Berger et al., 2012; Pan et al., 2013). Finally, the function of several ISGs is to help the IFN-induced cell to return to homeostasis (Malireddi and Kanneganti, 2013; Chen et al., 2017). Interestingly, as these ISGs decrease IFN signaling, they have proviral effects.

\section{HCV Evasion from Immune System}

Given the potent antiviral properties of ISGs, it is not surprising that HCV has evolved to hide from cellular sensors, block IFN induction and interfere with the action of several antiviral factors. This is achieved by several viral proteins and by the HCV-mediated induction of cellular ISGs that function as negative regulators of the IFN pathway (Arnaud et al., 2010; Imran et al., 2012; Horner and Gale, 2013; Oshiumi et al., 2013a; Gokhale et al., 2014; Yang and Zhu, 2015).

NS3-NS4A is one of the most relevant factors in the HCV evasion strategy. The protease interferes with the signaling induced by the major HCV sensors by cleaving and inactivating MAVS, TRIF, a TLR3 signaling adaptor protein, and Riplet E3 ubiquitin ligase, required for RIG-I ubiquitination, binding to TRIM25 and activation (Foy et al., 2005; Li et al., 2005; Meylan et al., 2005; Oshiumi et al., 2010; Gokhale et al., 2014). Other relevant viral factors are NS4A/B, NS5A and the core proteins, which function by inhibiting the transport of MHC Class I molecules to the cell surface and by blocking the STAT pathway. Core upregulates the protein phosphatase PP2Ac or SOCS3, leading to reduced STAT1 phosphorylation and IFN signaling blockade (Bode et al., 2003; Duong et al., 2004).

Interestingly, several factors with a proven antiviral role against different viruses favor HCV replication. These include the non-canonical sensors PKR and DDX3X. As mentioned above, these factors help IFN synthesis and therefore have an antiviral function. However, induction of IKK $\alpha$ by DDX3X induces the expression of lipogenic genes required by $\mathrm{HCV}$ for nucleocapsid assembly (Fullam and Schröder, 2013; Li Q. et al., 2013; Pène et al., 2015). PKR blocks cap-dependent translation of viral proteins by eIF $2 \alpha$ phosphorylation. Remarkably, in the case of $\mathrm{HCV}$, the IRES does not require eIF2 $\alpha$ for translation (Garaigorta and Chisari, 2009). Instead, PKR blocks translation of transcripts induced soon after viral infection such as antiviral ISGs. Then, in HCV infection PKR blocks translation of cellular antiviral factors while it does not affect the translation of viral proteins.

ISG15 is another general antiviral factor that promotes $\mathrm{HCV}$ replication. ISG15 is an ubiquitin-like molecule that can be attached to proteins covalently. This ISGylation occurs co-transcriptionally. Therefore, after $\mathrm{HCV}$ infection, the IFN pathway induces ISG15 and the ISGylation machinery, which modifies newly synthesized proteins such as viral proteins and ISGs. IRF3, PKR, MxA, Stat1, Jak1, or RIG-I can be modified by ISGylation. Protein ISGylation changes protein structure and stability, affecting functionality. RIG-I ISGylation blocks RIG-I ubiquitination and functionality. This increases HCV replication by limiting IFN production (Kim et al., 2008; Broering et al., 2010).

Several ISGs are induced by IFN that allow the cell to return to homeostasis and therefore may function as proviral factors. Good examples are ubiquitin specific peptidase 18 (USP18), a protein inhibitor of activated STATs (PIAS) and a suppressor of cytokine signaling (SOCS). USP18 (UBP43) is a protease that displaces ISG15 from its targets and blocks IFN signaling by binding to the IFNAR2 receptor and interfering with JAK binding (Malakhova et al., 2006). The SUMO E3 ligase protein PIAS1 interacts with STAT1 or IRF3 and avoids their binding to DNA, decreasing the STAT1- or IRF3-induced IFN response (Liu et al., 1998; Li R. et al., 2013). SOCS1 and SOCS3 bind the JAK proteins or the IFN receptors and inhibit JAK activity and STAT binding (Yoshimura et al., 2007).

Similar to proteins, several miRNAs and lncRNAs are regulated during infection to promote or repress the antiviral pathway, exerting antiviral or proviral functions.

\section{LONG NON-CODING RNAs (IncRNAs)}

Long non-coding RNAs are non-protein coding transcripts longer that 200 nucleotides. Similarly to mRNAs, most lncRNAs are transcribed from RNA polymerase II and are capped at the $5^{\prime}$ end, spliced and polyadenylated (Birney et al., 2007; Guttman et al., 2009). Compared to mRNAs, most lncRNAs are expressed at lower levels, are more cell type-specific and localize preferentially to the nucleus (Djebali et al., 2012). LncRNAs genes are more numerous that coding genes (Iyer et al., 2015). Re-annotation of the cell transcriptome indicates that the human genome may contain more than 90.000 genes, being $\sim 60.000$ of them lncRNA genes.

Long non-coding RNAs are not easy to classify according to functionality, as the function of most of them is unknown. Instead, most lncRNA classifications are based on genomic localization compared to neighboring genes (Garitano-Trojaola et al., 2013). According to their location in the genome lncRNAs can be grouped into: (i) sense lncRNAs, those that overlap 
with one or more exons from another transcript in the same strand; (ii) antisense lncRNAs, those that overlap with one or more exons from another transcript in the opposite strand; (iii) bidirectional or divergent lncRNAs, those that share their promoter with another gene in the opposite strand and (iv) intergenic lncRNAs, those that are independent transcripts located between two genes (Figure 3). Interestingly, some lncRNAs act as regulators of neighboring genes. Therefore, the genomic location of a given lncRNA gene may help to predict its function. In line with this, enhancer RNAs or eRNAs are lncRNAs transcribed from enhancer regions that participate in enhancing transcription from the promoters of genes located in the same nuclear territory (Orom et al., 2010; Lai et al., 2013; Melo et al., 2013). For function, eRNAs and other lncRNAs need to act in cis, at their site of transcription. Instead, transacting lncRNAs function far from their site of synthesis. Both cis and trans-acting RNAs can regulate transcription by different mechanisms, including modifying epigenetic regulators and chromatin remodelers, and/or regulating transcription initiation or elongation. Other functions of lncRNAs in the nucleus are as splicing regulators or organizers of subnuclear structures (Tripathi et al., 2010; Mao et al., 2011). In the cytoplasm some may regulate mRNA translation and stability, protein transport or post-translational modifications (Willingham et al., 2005; Cesana et al., 2011; Carrieri et al., 2012; Yoon et al., 2012; Wang et al., 2014). As the function of most lncRNAs is unknown, it is expected that novel functions of lncRNAs will be discovered in the future. Functionality of lncRNAs normally requires a linear sequence or a secondary or tertiary structure that binds to DNA, proteins or other RNAs to form functional complexes. Thus, compared to mRNAs, lncRNAs tend to have structures with higher folding energies (Kertesz et al., 2010).

Over the last decade, lncRNAs have been proved to be key regulators of most cell processes, including cell proliferation, development or cell return to homeostasis (Li X. et al., 2013; Li J. et al., 2016). Therefore, lncRNAs are implicated in all kinds of diseases, including cancer (Prensner and Chinnaiyan, 2011; Wapinski and Chang, 2011; Harries, 2012; Spizzo et al., 2012; Hu et al., 2016). Further, IncRNAs are highly targeted by evolution, suggesting that they may play a relevant role in those processes with a strong evolutionary pressure (Ulitsky et al., 2011; Cech and Steitz, 2014; Marques and Ponting, 2014). One of the drivers of evolution is the antiviral response. In fact, we and other groups have shown that the expression of several lncRNAs is deregulated in response to viral infection.

\section{LncRNAs in Viral Infection}

Viral infections induce strong modifications in the coding and non-coding transcriptome of the infected cell. Infected cells may deregulate cellular lncRNAs and may express viral lncRNAs or chimeric lncRNAs formed by viral and cellular sequences. Many viruses have been shown to express viral lncRNAs. In fact, there are some plant pathogens (viroids and virusoids) whose genome is a lncRNA with replication capacity (Gago-Zachert, 2016; Shimura and Masuta, 2016). Animal viruses such as adenovirus, Epstein-Bar virus, HIV, cytomegaloviruses, flaviviruses, and herpesviruses encode non-coding RNAs that function to affect transcription and RNA stability, and control RNA interference, the antiviral response, the energy of the infected cell and viral pathogenesis (Fortes and Morris, 2016). Interestingly, integration of the $\mathrm{HBV}$ genome in repetitive sequences of the genome of

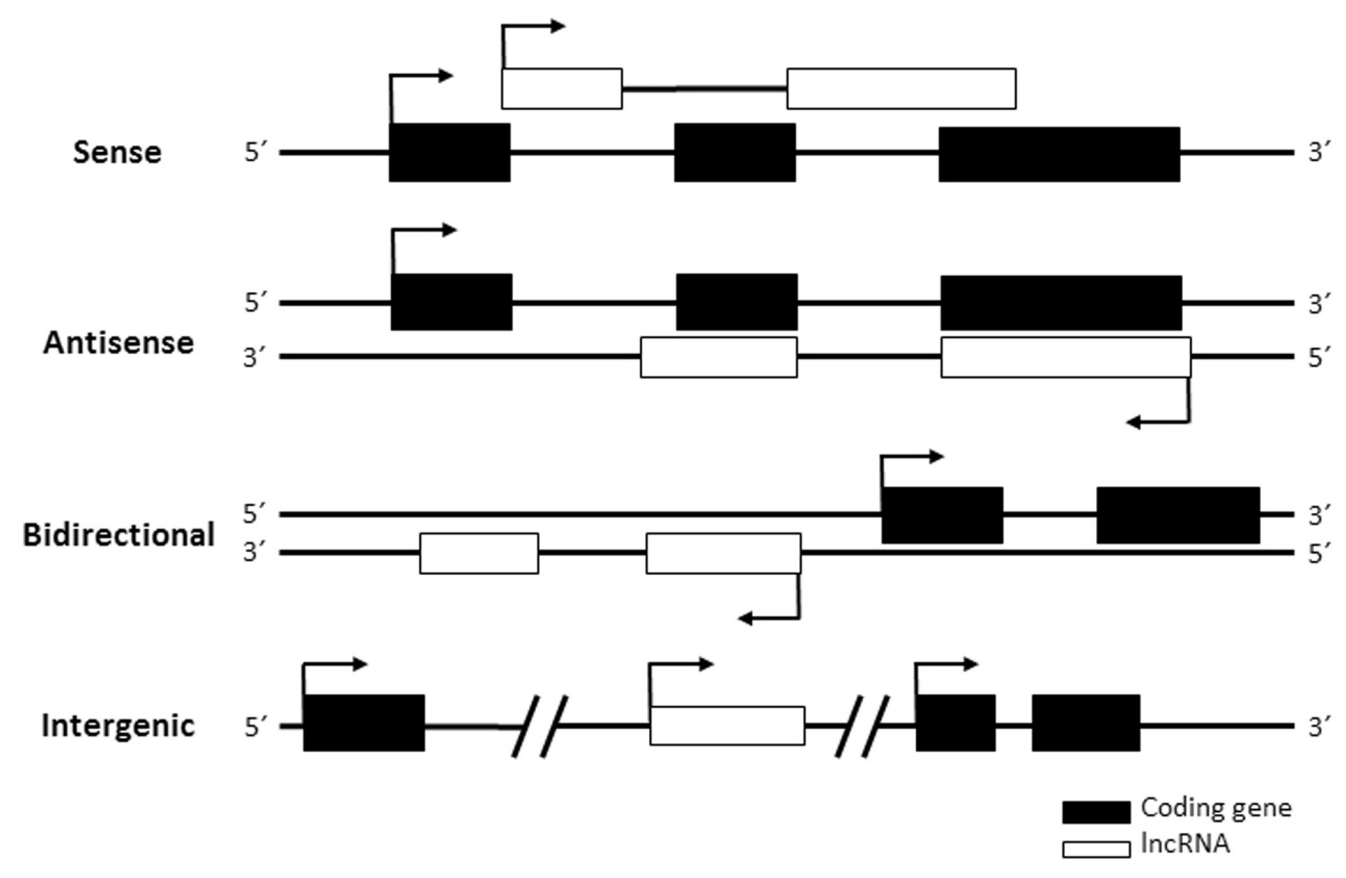

FIGURE 3 | Classification of IncRNAs. Arrows indicate transcription initiation. 
the infected cell produces fusions of the Hepatitis B X protein with host LINE1 sequences. These fusion transcripts, named HBx-LINE1, are found in many HBV-derived HCCs and have oncogenic effects (Lau et al., 2014; Moyo et al., 2016).

Cellular lncRNAs may be deregulated by viral proteins, in response to viral replication or in response to the antiviral pathways induced by infection. X protein from HBV decreases the tumor suppressor lncRNA Dreh (Huang et al., 2013), while the Nef protein from HIV decreases lncRNA NRON, leading to increased NFAT and transcription of viral genes (Imam et al., 2015; Lazar et al., 2016). Activation of TLR3, TLR4, or other canonical and non-canonical PAMP sensors and treatment with IFN or $\mathrm{TNF} \alpha$ (which triggers NF-кB) lead to changes in the expression of many lncRNAs that are deregulated in infected cells. Some of them have been shown to function as inducers or repressors of the innate antiviral response. This is the case of the negative regulator of antiviral response lncRNA (NRAV) (Ouyang et al., 2014). At homeostasis NRAV levels are high and silence MxA and IFITM3 expression by modulating H3K4me3 and $\mathrm{H} 3 \mathrm{~K} 27 \mathrm{me} 3$ marks. Upon infection with influenza virus or other viruses, NRAV levels are downregulated leading to an increase in MxA and IFITM3 expression. Then, overexpression of NRAV in mice produces hypersensitivity to influenza infection (Ouyang et al., 2016).

\section{LncRNAs in HCV Infection}

Similar to what has been described for other viruses, the lncRNA transcriptome is altered in HCV-infected cells (Figure 4). The deregulation of cellular lncRNAs may respond to $\mathrm{HCV}$ replication and viral protein expression or to the antiviral response induced against the infection. Further, lncRNAs from the viral genome may also be detected in infected cells.

\section{Viral LncRNAs}

Transcriptomic analysis of viral RNA in tissue-culture infected cells shows high levels of viral genome enriched in point mutations that generate quasi-species. Major internal deletions or fusions of the viral genome are not detected. Instead, there are HCV subgenomic RNAs that have lost the $5^{\prime}$ end of the IRES sequence, indicating that they could be non-coding RNAs of unknown function. These subgenomic RNAs are generated by the action of XRN1, a cellular exoribonuclease (Moon et al., 2015). XRN1-mediated degradation is not efficient, as miR-122 binding to the $5^{\prime}$ end of the viral RNA protects the genome, leading in part to the essential role played by miR-122 in HCV replication (Thibault et al., 2015).

\section{Cellular LncRNAs Induced by the Antiviral Response}

In some cases, it is difficult to discriminate whether the deregulation of certain lncRNAs in HCV-infected cells results from the induction of the antiviral response rather than from pure viral replication and viral protein expression (Figure 4 and Table 1). As a general rule, lncRNAs deregulated by the antiviral response are those altered in response to several viruses, different PAMPs and/or IFNs. Transcriptome analysis of cells treated with IFN has allowed the identification of several IFN-stimulated lncRNAs (ISRs) whose levels also increase after HCV infection.
They include NRIR, ISR2 (IFN-stimulated lncRNA2), ISR8, lncISG15, and BISPR (BST2 interferon stimulated positive regulator) (Carnero et al., 2014; Kambara et al., 2014, 2015; Barriocanal et al., 2015). Interestingly, all of these are located in the genome very close to ISGs that affect the replication of $\mathrm{HCV}$ and other viruses. Thus, NRIR is next to CMPK2 and viperin/RSAD, ISR2 is a neighbor of the GBP cluster, ISR8 is located tail to tail to the IRF1 transcription factor, lncISG15 is very close to ISG15 and BISPR to BST2.

The best known so far is NRIR. NRIR is conserved in the mouse and induced by IFN $\alpha$ in primary hepatocytes and several other cells, including primary keratinocytes, $\mathrm{HuH}$, $\mathrm{HeLa}$, 293 and Jurkat and mouse myoblast C2C12 cells (Kambara et al., 2014). As NRIR accumulates in the nucleus, it was originally hypothesized that it could be induced by IFN to help transcription of its neighboring genes, CMPK2 and viperin. Surprisingly, depletion of NRIR with two independent siRNAs led to increased expression of viperin and CMPK2 (Kambara et al., 2014). Similar results were observed after NRIR depletion in the levels of IFITM1, IFIT3, CXCL10 and ISG15, ISGs located far from NRIR in the genome, but not in other ISG tested. Unexpectedly, these results were observed in both IFN-treated and untreated cells. NRIR affected transcription and not mRNA stability. Therefore, NRIR is the first described lncRNA that acts as a negative regulator of the transcription of certain ISGs (Kambara et al., 2014). At basal levels, NRIR may help to silence NRIR-target ISGs. After IFN induction, NRIR levels may increase to repress transcription of target ISGs and allow the cell to return to homeostasis. It would be very interesting to understand how NRIR can silence transcription of both neighboring and distal genes. As indicated before, the mRNAs of several ISGs are induced in the liver of $\mathrm{HCV}$-infected patients. Therefore it is not surprising that the liver of HCV-infected patients has higher NRIR levels than non-infected controls (Kambara et al., 2014). As NRIR expression should decrease the levels of HCV antiviral factors such as IFITM1 or viperin, it is likely that NRIR benefits viral replication in infected livers. In fact, NRIR is a proviral factor, as depletion of NRIR in tissue culture upregulates transcription of several ISGs and decreases HCV replication.

ISR2, ISR8, IncISG15, and BISPR are induced early after IFN treatment. These lncRNAs are also upregulated in HCV-infected livers and cultured cells, probably, because of the induction of the IFN signaling pathway in these cells (Carnero et al., 2014; Barriocanal et al., 2015). In fact, ISR2, ISR8, IncISG15, and BISPR are also induced after infection with other viruses. Interestingly, ISR2 and ISR8 are induced more in response to HCV infection than in response to infection with adenovirus, Semliki Forest Virus (SFV) or influenza wild-type or mutant viruses that fail to block the IFN pathway (Carnero et al., 2014). Thus, ISR2 and ISR 8 could be induced by HCV also in an IFN-unrelated manner. Although the function of these lncRNAs is not known, ISR2, ISR8, and lncISG15 accumulate preferentially in the cell nucleus, where they could exert regulatory roles. In fact, the levels of these lncRNAs correlate significantly with the levels of their neighboring ISGs, suggesting either that these genes are co-regulated or that the IncRNA could control the expression of the neighboring ISG. In line with this, guilt-by-association 


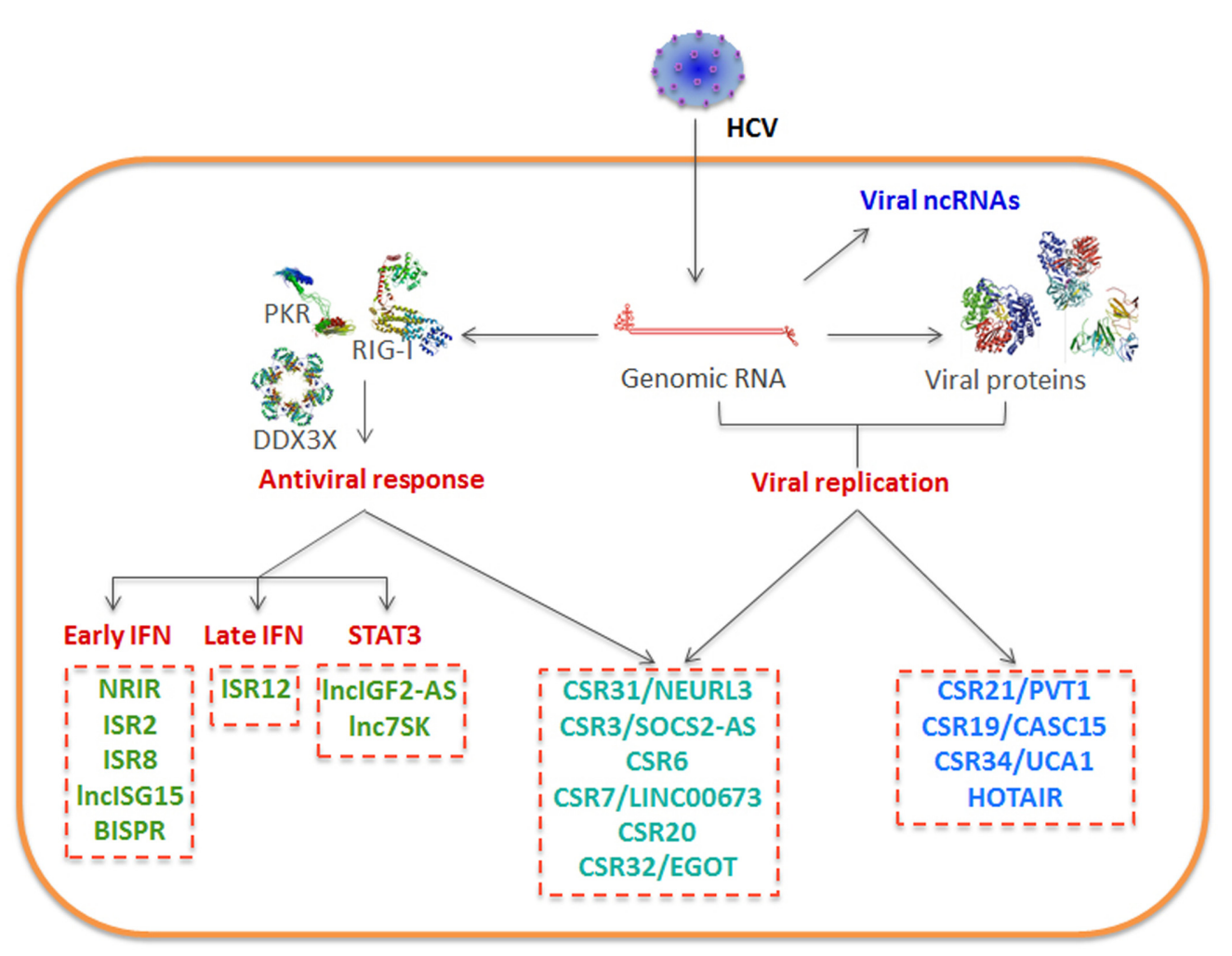

FIGURE 4 | Schematic of IncRNAs deregulated in HCV-infected cells. Viral RNA may be processed to viral ncRNAs. Viral replication, the antiviral response induced by the infection or the combination of both deregulate the levels of several cellular IncRNAs.

studies predict that ISR2 may be involved in the regulation of PAMP receptors and IFN activation and ISR8 may induce the IFN response and the immune system (Carnero et al., 2014).

The role of BISPR has been studied in more detail. BISPR was identified independently by two different groups working with IFN-treated HuH7 cells or primary hepatocytes (Barriocanal et al., 2015; Kambara et al., 2015). BISPR can be induced with IFN $\alpha$, IFN $\lambda$ and IFN $\gamma$, but not TNF $\alpha$. Induction with IFN $\alpha$ occurs early after treatment of all cell-lines tested, including primary keratinocytes and hepatocytes, or HuH7, A549, HeLa, Jurkat, or THP1 cell lines. Treatment of the cells with IFN and ruxolitinib, an inhibitor of the JAK/STAT pathway, or transfection of siRNAs that target STAT2 in IFN-treated cells, decreased BISRP levels significantly compared to control cells. Further, the BISPR promoter has conserved binding sequences for STAT1/2/IRF9, IRF1, and IRF7. Together, these results point to BISPR being a bona fide ISG. In fact, as BISPR and BST2/tetherin are located close by in a head-to-head orientation, the BISPR promoter could work as a bidirectional promoter. Not surprisingly, there is a significant positive correlation between the expression of BISPR and BST2/tetherin (Barriocanal et al., 2015; Kambara et al., 2015). Depletion of BISPR with siRNAs in IFN-treated cells leads to decreased levels of BST2. Unlike what has been shown before for NRIR, downregulation of BISPR does not affect the levels of any of the other ISGs evaluated. The molecular mechanism of BISPR action is unknown. However, experiments performed to date are consistent with the following hypothesis: the IFN pathway induces first the expression of BISPR, which is retained in the nucleus and acts in trans to induce transcription of BST2/tetherin probably by modulating the effect of the Polycomb complex PRC2 (Kambara et al., 2015). Thus, (i) BISPR induction after IFN-treatment precedes induction of BST2, (ii) BISPR accumulates preferentially in the nucleus of the cell, (iii) overexpression of BISPR increases BST2 levels, suggesting that BISPR does not require to be expressed from a specific genomic position for functionality, (iv) stability of BST2 is not affected after BISPR deregulation, indicating that regulation is at the level of transcription and (v) downregulation of the functional subunit of the PRC2 silencing complex, EZH2, leads to BST2 upregulation, suggesting that BISPR could function by counteracting the suppressive action of PRC2 (Kambara et al., 2015). As BISPR is a positive regulator of BST2, involved in impeding virion release, increased expression of BISPR by IFN could lead to decreased budding of HCV viral particles (Neil et al., 2008; Dafa-Berger et al., 2012; Barriocanal et al., 2015; Kambara et al., 2015). Thus, induction of IFN-induced lncRNAs may be antiviral (as in the case of BISPR) or proviral (as in the case of NRIR) for HCV replication.

Finally, IncRNAs could be induced by a secondary pathway activated by IFN signaling. This is the case of ISR12, a 
TABLE 1 | List of IncRNAs deregulated in HCV-infected cells.

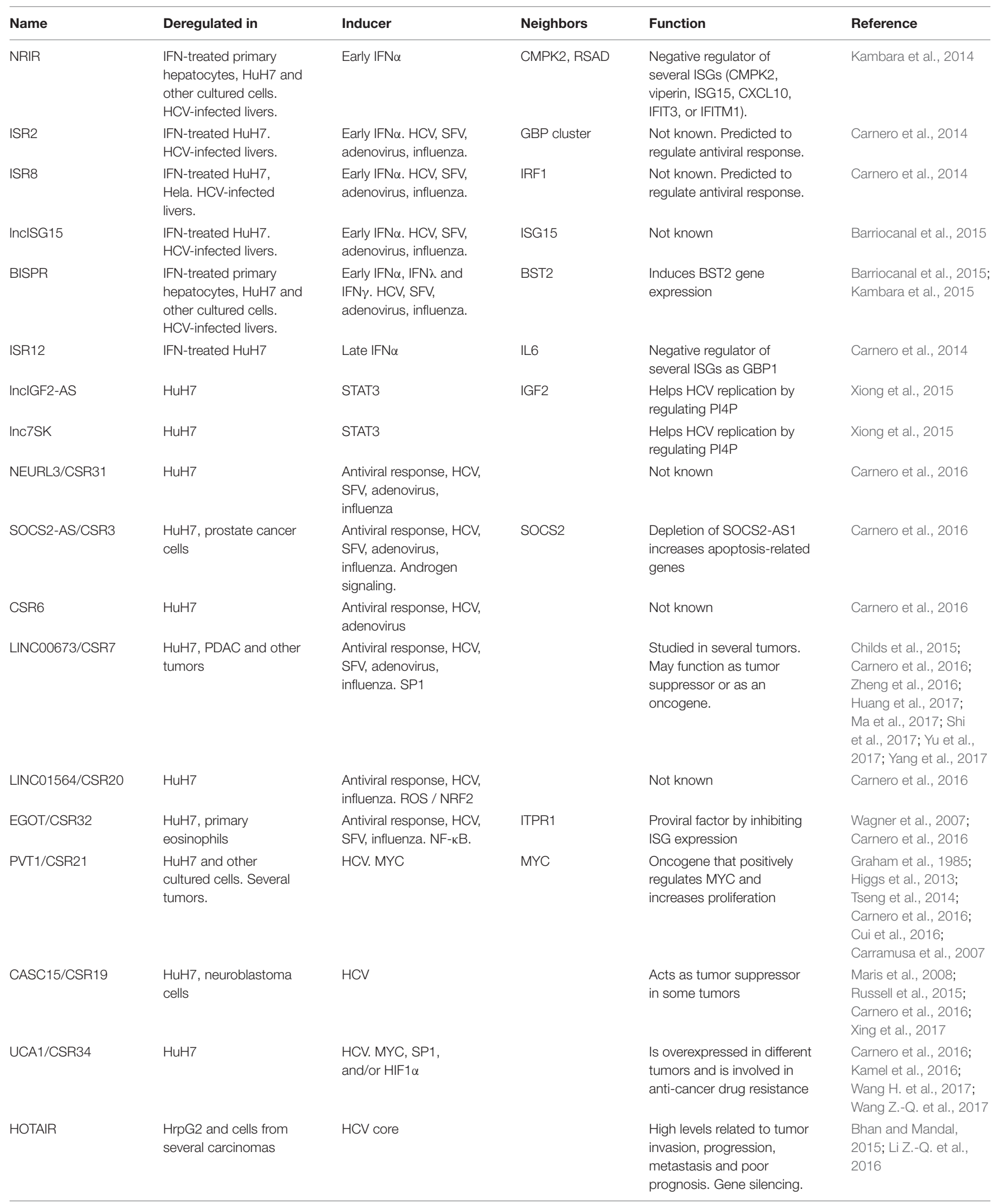

See the text for details. 
lncRNA that is induced at late times post-IFN treatment and that accumulates preferentially in the cell nucleus (Carnero et al., 2014). ISR12 is located close to IL6, an important pro-inflammatory cytokine. However, the levels of ISR12 and IL6 do not correlate, indicating that IL6 is not regulated by ISR12. In turn, ISR12 depletion with two independent siRNAs leads to increased expression of several ISGs, including GBP1 (Carnero and Fortes, 2016). Thus, as was the case with NRIR, ISR12 is a negative regulator of the expression of ISGs located far away in the genome which could act as a proviral gene. However, ISR12 is not significantly induced in the liver of patients infected with $\mathrm{HCV}$, compared to non-infected patients.

IFN induces STAT3, which functions as a negative regulator of the type I IFN pathway (Wang et al., 2011). STAT3 is a transcription factor induced by stress, growth factors, IL6 and other cytokines. STAT3 can also be induced by HCV infection, as expression of core and other viral proteins induces ROS (Yoshida et al., 2002; Waris et al., 2005; Machida et al., 2006). Then, STAT3 induces lncIGF2-AS and lnc7SK, whose inhibition blocks viral replication by decreasing PI4KIIIalpha, required for MW reorganization (Xiong et al., 2015). Therefore, STAT3 can help viral replication by blocking the IFN pathway and by upregulating lncRNAs that favor MW formation.

\section{Cellular LncRNAs Induced by the Antiviral Response and HCV Infection}

Among IFN-induced lncRNAs, those that are induced mildly by IFN or PAMPs and strongly by HCV infection deserve special mention (Carnero et al., 2016) (Figure 4 and Table 1). NEURL3, described as a pseudogene, belongs to this group. NEURL3 is induced 12 fold by IFN $\alpha, 31$ fold after transfection with the dsRNA analog pI:C and almost 2000 fold after HCV infection. Therefore, NEURL3 may be classified as a transcript induced by the antiviral response and other signaling pathways activated in HCV-infected cells. NEURL3 and other lncRNAs that belong to this group were identified after comparing the transcriptome of control cells, cells infected with HCV, cells treated with IFN $\alpha$ and cells that were first infected and then treated with IFN $\alpha$. LncRNAs induced after HCV infection were called CSRs, from HCV stimulated RNAs (Carnero et al., 2016). CSR3, CSR6, CSR7, CSR20, CSR31/NEURL3, and CSR32 were significantly induced after treatment with pI:C and 4-130 fold more, in cells infected with $\mathrm{HCV}$.

Infection with other viruses also induces the expression of these CSRs, although to milder levels than infection with HCV. CSR3, 7, and 31 are induced after infection with adenovirus, influenza, SFV and HCV, preferentially, with mutant versions that fail to block the IFN pathway; CSR6 is only induced in response to adenovirus, and $\mathrm{HCV}$; CSR20 in response to influenza virus and $\mathrm{HCV}$ and CSR32 in response to all RNA viruses tested (HCV, influenza, SFV) but not in response to DNA viruses (adenovirus or HBV) (Carnero et al., 2016). Little is known about the function of these lncRNAs, in relation with HCV infection, with the exception of CSR32/EGOT.

CSR32/EGOT (eosinophil granule ontogeny transcript) is a lncRNA present in all placental mammals that contains several evolutionary conserved and thermodynamically stable secondary structures (Rose and Stadler, 2011). EGOT was first described as a lncRNA preferentially expressed in mature eosinophils where it serves to regulate the expression of toxic eosinophil proteins (Wagner et al., 2007). However, GTEx analysis of the human transcriptome indicates that EGOT is preferentially expressed in the breast and vagina, pancreas, pituitary and kidney cortex, while TCGA analysis shows that EGOT is upregulated in liver, lung and thyroid carcinomas and downregulated in prostate, breast and kidney tumors, where low levels correlate with poor prognosis (Lonsdale et al., 2013; Li J. et al., 2015). Later, it was shown that EGOT is a polyadenylated non-coding RNA induced after infection with HCV in cell lines and in the liver of $\mathrm{HCV}$-infected patients. Interestingly, inhibition of EGOT in $\mathrm{HCV}$-infected cells results in decreased viral genomes, viral titers, and viral proteins (Carnero et al., 2016). Similar results are observed when EGOT is depleted in cells infected with SFV. These results indicate that EGOT is a proviral factor. The proviral function results from EGOT-mediated downregulation of ISGs. This has been observed in massive guilt-by-association studies, where EGOT levels correlate negatively with the levels of genes related to the immune response (Carnero et al., 2016). Further, inhibition of EGOT leads to increased levels of several ISGs including GBP1, ISG15, Mx1, BST2, ISG56, IFI6 and IFITM1, some of which have already been described as blocking HCV or SFV entry, replication or release (Landis et al., 1998; Itsui et al., 2009; Raychoudhuri et al., 2011; Wilkins et al., 2013; Amet et al., 2014; Ooi et al., 2015). Surprisingly, EGOT is a proviral lncRNA induced in response to the antiviral response. Results published so far are in agreement with the following: (i) HCV viral RNA is sensed in the cytoplasm a few hours after infection, as EGOT increases significantly in cells infected with $\mathrm{HCV}$ for $5 \mathrm{~h}$ or with $\mathrm{UV}$ inactivated viruses unable to replicate; (ii) then, viral replication increases EGOT levels further, up to 800 fold, as EGOT decreases in infected cells when replication is inhibited with HCV antivirals; (iii) incoming or replicating viral RNA is sensed by RIG-I and the noncanonical sensor PKR; (iv) these sensors induce transcription by IRF3 and NF- $\kappa$; (v) NF- $\kappa$ B is involved in EGOT induction, as induction of the NF- $\kappa \mathrm{B}$ pathway with $\mathrm{TNF} \alpha$ also results in increased levels of EGOT; (vi) when viral proteins are translated, they block the IFN signaling and synthesis pathways, but they induce NF- $\mathrm{B}$, which maintains high EGOT levels, (vii) EGOT is a lncRNA expressed from an enhancer region, as the EGOT genomic region has a high ratio of histone 3 lysine 4 monomethylation versus trimethylation (Heintzman et al., 2007), (viii) EGOT decreases the expression of ISGs, which benefits viral replication, encapsidation, and release (Carnero et al., 2016).

As is the case with CSR32/EGOT, which is induced by the antiviral and the NF- $\mathrm{B}$ pathways, other CSRs are induced by other signaling routes activated after $\mathrm{HCV}$ infection. $\mathrm{HCV}$ infection activates ROS-dependent and independent mechanisms that activate NRF2, which, in turn, upregulates CSR20/RP11-345L23.1/LINC01564 (Burdette et al., 2010; Ivanov et al., 2011; Ashouri et al., 2016). HCV also induces androgen signaling and the transcription factor SP1, which activates transcription of CSR3/SOCS2-AS1 and CSR7/LINC00673, 
respectively (Kanda et al., 2008; Xiang et al., 2010; Misawa et al., 2016; Zheng et al., 2016).

CSR3/SOCS2-AS1, located in the genome antisense to the Suppressor of Cytokine Signaling-2 (SOCS2) gene, is induced by androgen receptor signaling in prostate cancer cells and promotes androgen-dependent cell growth (Misawa et al., 2016). Depletion of SOCS2-AS1 increases apoptosis-related genes by modulating the epigenetic control of target genes of the androgen receptor signaling pathway.

CSR7/LINC00673 has been studied in several tumors. In human pancreatic ductal adenocarcinoma (PDAC), LINC00673 was significantly downregulated compared to peritumoral tissue. Low expression of the lncRNA correlated with higher occurrence of metastasis, poor differentiation and poor survival. Decreased levels of the lncRNA were shown to promote cell proliferation by repressing the homeobox HNF1A. These results indicate that LINC00673 could be a tumor suppressor (Yang et al., 2017). In fact, detailed studies show that a mutation in the region of LINC00673 is associated with susceptibility to pancreatic cancer (Childs et al., 2015). A G to A change in exon 4 creates a target site for miR-1231 and decreased levels of LINC00673. Then, LINC00673 does not favor the binding between the E3 ubiquitin ligase PRPF19 and PTPN11 and PTPN11 is not ubiquitinated and degraded by the proteasome. High levels of PTPN11 increase SRC-ERK oncogenic signaling and decrease the STAT1 antitumor response, leading to increased risk of tumorigenesis (Zheng et al., 2016). However, LINC00673 has also been described as significantly upregulated in gastric, nonsmall cell lung cancer and tongue squamous cell carcinomas, where the levels correlate with poor prognosis (Shi X. et al., 2016; Huang et al., 2017; Ma et al., 2017; Yu et al., 2017). In cells derived from these tumors, downregulation of LINC00673 results in decreased cell proliferation, invasion and migration and increased apoptosis. In non-small cell lung cancer and gastric cancer cells, overexpression of LINC00673 has the opposite effect, indicating that this lncRNA is working in trans (Shi X. et al., 2016; Huang et al., 2017; Ma et al., 2017). In these cells, it has been shown that LINC00673 works by interacting with the epigenetic regulators LSD1 and EZH2. RNA immunoprecipitation, RNA pull down and ChIP experiments performed with gastric cancer cells show that LINC00673 binds to LSD1 and the Polycomb essential factor EZH2 and induces repression of KLF2 and LATS2. In non-small cell lung cancer cells binding of LINC00673 to $\mathrm{EZH} 2$ decreases transcription of HOXA5, a tumor suppressor that blocks metastasis by affecting cytoskeletal remodeling ( $\mathrm{Ma}$ et al., 2017).

In summary, several lncRNAs are induced in HCV-infected cells both by IFN signaling and alternative pathways. Surprisingly, most of them play important roles in the proliferation and migration of different tumors. Then, we believe that these oncogenic lncRNAs could play a role in the higher incidence of HCC observed in patients infected with $\mathrm{HCV}$.

\section{Cellular LncRNAs Induced by HCV Infection}

Similarly, several of the lncRNAs that are induced by HCV infection and not by the infection with other viruses or by the antiviral response have also been described as exerting oncogenic functions (Carnero et al., 2016) (Figure 4 and Table 1). These include CSR21/PVT1, CSR19/CASC15, and CSR34/UCA1. We believe that the proliferating environment induced by the expression of oncogenic lncRNAs may be beneficial for HCV replication. In turn, these lncRNAs could induce cell division and other pro-carcinogenic pathways that may contribute to $\mathrm{HCC}$ development in HCV-infected patients. In line with this, it has been described that the $\mathrm{X}$ protein of $\mathrm{HBV}$ decreases the expression of the tumor suppressor lncRNA DREH (Huang et al., 2013).

Hepatitis C virus infection increases the levels of CSR21/PVT-1 around 10 fold. PVT1 is plasmocytoma variant translocation 1 gene (PVT1), an oncogene described as a site of retroviral insertions in murine $\mathrm{T}$ lymphomas. Soon after PVT1 identification it was suggested that PVT1 functions to control the neighboring oncogene MYC (Graham et al., 1985). Later, it was shown that PVT1 is upregulated in other tumors, including HCCs (Cui et al., 2016). In fact, it has been described that Hepatitis B virus genome integrates in the region located between MYC and PVT-1 in 12.4\% of HCCs that develop early after viral infection and that viral integration correlates with upregulation of MYC and PVT-1, and, most probably, with the development of HCC (Yan et al., 2015). PVT-1 expression is induced by MYC and functions to increase MYC levels, resulting in an oncogenic positive regulatory loop (Carramusa et al., 2007; Tseng et al., 2014). HCV infection could cause increased PVT1 levels by NS5A-mediated induction of MYC (Higgs et al., 2013). Although PVT1's oncogenic role is closely associated with MYC, the PVT1 gene also encodes for several miRNAs and participates in different DNA rearrangements that lead to aberrant expression and tumorigenesis (Cui et al., 2016). Interestingly, PVT1 transcription also generates a circular RNA that abolishes senescence by sequestering let-7 and allowing accumulation of let7-targetted proliferative genes (Panda et al., 2017).

CSR19/CASC15 increases their levels in HCV-infected cells around sevenfold. CASC15 is a cancer susceptibility candidate with SNPs significantly associated with aggressive neuroblastoma (Maris et al., 2008). Decreased levels of a short isoform of CASC15 associate with poor prognosis and advanced neuroblastoma and downregulation of this isoform increases cell growth and migration (Russell et al., 2015). Similarly, a CASC15 transcript named CANT1 lncRNA functions as a tumor suppressor in Uveal Melanoma (Xing et al., 2017). CANT1 expression reduces tumor formation and metastatic potential by inducing the expression of JPX, FTX, and XIST.

HOX transcript antisense intergenic RNA (HOTAIR) is induced threefold in cells expressing $\mathrm{HCV}$-core protein (Li Z.-Q. et al., 2016). HOTAIR blocks SIRT1 expression by promoter methylation leading to an altered glucose and lipid metabolism that may benefit $\mathrm{HCV}$ replication. HOTAIR is upregulated in many tumors, including breast, esophageal, lung, liver and gastric cancers, where high levels of HOTAIR correlate with tumor invasion, progression, metastasis, and poor prognosis. HOTAIR controls cell growth and apoptosis, metastasis, angiogenesis, DNA repair and metabolism by binding 
key epigenetic regulators such as PRC2 and LSD1 and inducing gene silencing (Bhan and Mandal, 2015).

CSR34/UCA1 is induced in HCV-infected cells over 20 fold, probably by activation of MYC, SP1 and/or HIF1 $\alpha$ (Nasimuzzaman et al., 2007; Carnero et al., 2016; Wang H. et al., 2017; Wang Z.-Q. et al., 2017). Reactive oxygen species (ROS) induced by $\mathrm{HCV}$ inhibit $\mathrm{C} / \mathrm{EBP} \alpha$ and stabilize HIF- $1 \alpha$, which are a negative and a positive regulator of UCA1 expression, respectively (Miura et al., 2008; Nishina et al., 2008). Urothelial carcinoma associated 1 (UCA1) has been involved in anticancer drug resistance in several tumors (Wang $H$. et al., 2017). Therefore, UCA1 is overexpressed in different cancers and correlates with poor prognosis. The role of UCA1 in drug resistance is mediated by UCA1 interference with miR27b, miR18a, miR16 and other miRNAs, depending on the tumor cell studied. This increases AKT/mTOR/HIFla and Wnt/bcatenin signaling which in turn increase MDR1 expression and drug resistance (Wang H. et al., 2017).

UCA1 together with IncRNA WRAP53 are increased in the liver and serum of HCV-derived HCC compared to HCVderived cirrhotic tissues and healthy livers (Kamel et al., 2016). In fact, several studies have been performed to identify HCVinduced lncRNAs in HCV-related HCCs. The patients chosen had developed liver cirrhosis or HCC in response to $\mathrm{HCV}$ infection. In most cases, lncRNA expression profiles of these livers were compared to those of healthy livers. Therefore, it is unclear whether the identified lncRNAs are deregulated by the development of liver cirrhosis or HCC, by HCV infection or by a combination of these factors. In HCV-derived HCCs LINC01419 is upregulated and AF070632 is deregulated (Zhang et al., 2015). However, LINC01419 and other lncRNAs such as ANRIL and HOTTIP are also upregulated compared to adjacent or healthy tissue in both HCV-related and HBV-related HCCs, suggesting that these lncRNAs could be related to all HCCs (Zhang et al., 2015, 2016). Patients with HCV-related hepatic fibrosis show increased levels of the TGF $\beta$-induced lncRNAATB compared to healthy controls (Yuan et al., 2014; Fu et al., 2017). Interestingly, LX-2 cells, a line of the fibrosis-inducer hepatic stellate cells, upregulates LncRNA-ATB when incubated with conditional medium from a liver cell expressing HCV core protein. Experiments agree with a model linking HCV infection and liver fibrosis, in which expression of core protein in liver cells induces LncRNA-ATB in hepatic stellate cells, which respond with increased collagen secretion and fibrosis (Fu et al., 2017).

\section{REFERENCES}

AASLD/IDSA HCV Guidance Panel (2015). Hepatitis C guidance: AASLD-IDSA recommendations for testing, managing, and treating adults infected with hepatitis C virus. Hepatology 62, 932-954. doi: 10.1002/hep.27950

Adams, R. L., Pirakitikulr, N., and Pyle, A. M. (2017). Functional RNA structures throughout the Hepatitis C Virus genome. Curr. Opin. Virol. 24, 79-86. doi: 10.1016/j.coviro.2017.04.007

Amet, T., Byrd, D., Hu, N., Sun, Q., Li, F., Zhao, Y., et al. (2014). BST-2 expression in human hepatocytes is inducible by all three types of interferons and restricts production of hepatitis C virus. Curr. Mol. Med. 14, 349-360. doi: 10.2174/ 1566524013666131118111719

\section{CONCLUDING REMARKS}

Taken together, the results published so far, are in agreement regarding the key role of lncRNAs in $\mathrm{HCV}$ replication, modulation of the antiviral response and, probably, the development of liver fibrosis and HCC in infected patients. However, further studies are required to identify lncRNAs deregulated at different stages of the viral cycle and of the progression to chronicity, fibrosis, cirrhosis, and HCC. Deregulated lncRNAs should be compared to those deregulated in HCC and cirrhotic livers of different etiologies, including HBV infection and alcohol abuse. Functional studies will help to determine the relevance of the lncRNAs for viral replication and disease progression and the molecular mechanisms involved. Deciphering the bidimensional and tridimensional structure of the RNAs and identifying their DNA, RNA and/or proteininteracting partners will be essential to understand functionality. The results obtained so far allow us to suggest that the study of HCV-related lncRNAs will aid in the identification of lncRNAs that function as proviral or antiviral agents, positive or negative regulators of the immune system, oncogenes, tumor suppressors, metabolic regulators, or profibrogenic factors. Research on these lncRNAs may aid in the development of novel therapies for the treatment of immune and infection diseases and cancer.

\section{AUTHOR CONTRIBUTIONS}

$\mathrm{MB}$ and $\mathrm{PF}$ revised all the literature, wrote the review and made the figures.

\section{ACKNOWLEDGMENTS}

This work was supported by grants from the Spanish Department of Science (SAF2012-40003, SAF2015-70971-R), Instituto de Salud Carlos III (ISCIII) (PI16/0845), grant Ortiz de Landazuri from the Government of Navarra, Fundacio La Marato de TV3 (20132132), European FEDER funding and by the project RNAREG (CSD2009-00080), funded by the Ministry of Science and Innovation under the program CONSOLIDER INGENIO 2010. MB is the recipient of a FPI fellowship.

Ariumi, Y., Kuroki, M., Abe, K., Dansako, H., Ikeda, M., Wakita, T., et al. (2007). DDX3 DEAD-box RNA helicase is required for hepatitis C virus RNA replication. J. Virol. 81, 13922-13926. doi: 10.1128/JVI. 01517-07

Arnaud, N., Dabo, S., Maillard, P., Budkowska, A., Kalliampakou, K. I., Mavromara, P., et al. (2010). Hepatitis C virus controls interferon production through PKR activation. PLOS ONE 5:e10575. doi: 10.1371/journal.pone. 0010575

Ashouri, A., Sayin, V. I., Van den Eynden, J., Singh, S. X., Papagiannakopoulos, T., and Larsson, E. (2016). Pan-cancer transcriptomic analysis associates long non-coding RNAs with key mutational driver events. Nat. Commun. 7:13197. doi: $10.1038 /$ ncomms 13197 
Atoom, A. M., Taylor, N. G. A., and Russell, R. S. (2014). The elusive function of the hepatitis C virus p7 protein. Virology 46, 377-387. doi: 10.1016/j.virol.2014. 04.018

Barriocanal, M., Carnero, E., Segura, V., and Fortes, P. (2015). Long non-coding RNA BST2/BISPR is induced by IFN and regulates the expression of the antiviral factor Tetherin. Front. Immunol. 5:655. doi: 10.3389/fimmu.2014. 00655

Bassendine, M. F., Sheridan, D. A., Bridge, S. H., Felmlee, D. J., and Neely, R. D. G. (2013). Lipids and HCV. Semin. Immunopathol. 35, 87-100. doi: 10.1007/ s00281-012-0356-2

Bhamidimarri, K. R., Satapathy, S. K., and Martin, P. (2017). Hepatitis C virus and liver transplantation. Gastroenterol. Hepatol. 13, 214-220.

Bhan, A., and Mandal, S. S. (2015). LncRNA HOTAIR: a master regulator of chromatin dynamics and cancer. Biochim. Biophys. Acta 1856, 151-164. doi: 10.1016/j.bbcan.2015.07.001

Binder, M., Eberle, F., Seitz, S., Mücke, N., Hüber, C. M., Kiani, N., et al. (2011). Molecular mechanism of signal perception and integration by the innate immune sensor retinoic acid-inducible gene-I (RIG-I). J. Biol. Chem. 286, 27278-27287. doi: 10.1074/jbc.M111.256974

Birney, E., Stamatoyannopoulos, J. A., Dutta, A., Guigó, R., Gingeras, T. R., Margulies, E. H., et al. (2007). Identification and analysis of functional elements in $1 \%$ of the human genome by the ENCODE pilot project. Nature 447, 799-816. doi: 10.1038/nature05874

Bode, J. G., Ludwig, S., Ehrhardt, C., Albrecht, U., Erhardt, A., Schaper, F., et al. (2003). IFN- $\alpha$ antagonistic activity of HCV core protein involves induction of suppressor of cytokine signaling-3. FASEB J. 17, 488-490. doi: 10.1096/fj.020664fje

Boisvert, M., and Shoukry, N. H. (2016). Type III interferons in hepatitis C virus infection. Front. Immunol. 7:628. doi: 10.3389/fimmu.2016.00628

Boulant, S., Montserret, R., Hope, R. G., Ratinier, M., Targett-Adams, P., Lavergne, J.-P., et al. (2006). Structural determinants that target the hepatitis $C$ virus core protein to lipid droplets. J. Biol. Chem. 281, 22236-22247. doi: 10.1074/jbc. M601031200

Brimacombe, C. L., Grove, J., Meredith, L. W., Hu, K., Syder, A. J., Flores, M. V., et al. (2011). Neutralizing antibody-resistant hepatitis C virus cell-to-cell transmission. J. Virol. 85, 596-605. doi: 10.1128/JVI.01592-10

Broering, R., Zhang, X., Kottilil, S., Trippler, M., Jiang, M., Lu, M., et al. (2010). The interferon stimulated gene 15 functions as a proviral factor for the hepatitis $\mathrm{C}$ virus and as a regulator of the IFN response. Gut 59, 1111-1119. doi: 10.1136/ gut.2009.195545

Burdette, D., Olivarez, M., and Waris, G. (2010). Activation of transcription factor Nrf2 by hepatitis C virus induces the cell-survival pathway. J. Gen. Virol. 91, 681-690. doi: 10.1099/vir.0.014340-0

Carnero, E., Barriocanal, M., Prior, C., Pablo Unfried, J., Segura, V., Guruceaga, E., et al. (2016). Long noncoding RNA EGOT negatively affects the antiviral response and favors HCV replication. EMBO Rep. 17, 1013-1028. doi: 10.15252/ embr.201541763

Carnero, E., Barriocanal, M., Segura, V., Guruceaga, E., Prior, C., Borner, K., et al. (2014). Type I interferon regulates the expression of long non-coding RNAs. Front. Immunol. 5:548. doi: 10.3389/fimmu.2014.00548

Carnero, E., and Fortes, P. (2016). HCV infection, IFN response and the coding and non-coding host cell genome. Virus Res. 212, 85-102. doi: 10.1016/j.virusres. 2015.10.001

Carramusa, L., Contino, F., Ferro, A., Minafra, L., Perconti, G., Giallongo, A., et al. (2007). The PVT-1 oncogene is a Myc protein target that is overexpressed in transformed cells. J. Cell. Physiol. 213, 511-518. doi: 10.1002/jcp.21133

Carrieri, C., Cimatti, L., Biagioli, M., Beugnet, A., Zucchelli, S., Fedele, S., et al. (2012). Long non-coding antisense RNA controls Uchl1 translation through an embedded SINEB2 repeat. Nature 491, 454-457. doi: 10.1038/nature11508

Catanese, M. T., Uryu, K., Kopp, M., Edwards, T. J., Andrus, L., Rice, W. J., et al. (2013). Ultrastructural analysis of hepatitis C virus particles. Proc. Natl. Acad. Sci. U.S.A. 110, 9505-9510. doi: 10.1073/pnas.1307527110

Cech, T., and Steitz, J. (2014). The noncoding RNA revolution? Trashing old rules to forge new ones. Cell 157, 77-94. doi: 10.1016/j.cell.2014.03.008

Cento, V., Nguyen, T. H. T., Di Carlo, D., Biliotti, E., Gianserra, L., Lenci, I., et al. (2017). Improvement of ALT decay kinetics by all-oral HCV treatment: role of NS5A inhibitors and differences with IFN-based regimens. PLOS ONE 12:e0177352. doi: 10.1371/journal.pone.0177352
Cesana, M., Cacchiarelli, D., Legnini, I., Santini, T., Sthandier, O., Chinappi, M., et al. (2011). A long noncoding RNA controls muscle differentiation by functioning as a competing endogenous RNA. Cell 147, 358-369. doi: 10.1016/ j.cell.2011.09.028

Chang, C.-C., Hsu, H.-J., Yen, J.-H., Lo, S.-Y., and Liou, J.-W. (2017). A sequence in the loop domain of hepatitis $\mathrm{C}$ virus $\mathrm{E} 2$ protein identified in silico as crucial for the selective binding to human CD81. PLOS ONE 12:e0177383. doi: 10.1371/ journal.pone. 0177383

Chang, K.-S., Jiang, J., Cai, Z., and Luo, G. (2007). Human apolipoprotein e is required for infectivity and production of hepatitis $\mathrm{C}$ virus in cell culture. J. Virol. 81, 13783-13793. doi: 10.1128/JVI.01091-07

Chen, K., Liu, J., and Cao, X. (2017). Regulation of type I interferon signaling in immunity and inflammation: a comprehensive review. J. Autoimmun. 83, 1-11. doi: 10.1016/j.jaut.2017.03.008

Cheng, J.-C., Yeh, Y.-J., Tseng, C.-P., Hsu, S.-D., Chang, Y.-L., Sakamoto, N., et al. (2012). Let-7b is a novel regulator of hepatitis $\mathrm{C}$ virus replication. Cell. Mol. Life Sci. 69, 2621-2633. doi: 10.1007/s00018-012-0940-6

Chevaliez, S., and Pawlotsky, J.-M. (2008). Diagnosis and management of chronic viral hepatitis: antigens, antibodies and viral genomes. Best Pract. Res. Clin. Gastroenterol. 22, 1031-1048. doi: 10.1016/j.bpg.2008. 11.004

Childs, E. J., Mocci, E., Campa, D., Bracci, P. M., Gallinger, S., Goggins, M., et al. (2015). Common variation at 2p13.3,3q29, 7p13 and 17q25.1 associated with susceptibility to pancreatic cancer. Nat. Genet. 47, 911-916. doi: 10.1038/ng. 3341

Choo, Q. L., Kuo, G., Weiner, A. J., Overby, L. R., Bradley, D. W., and Houghton, M. (1989). Isolation of a cDNA clone derived from a blood-borne non-A, non-B viral hepatitis genome. Science 244, 359-362. doi: 10.1126/ science. 2523562

Choo, Q. L., Richman, K. H., Han, J. H., Berger, K., Lee, C., Dong, C., et al. (1991). Genetic organization and diversity of the hepatitis C virus. Proc. Natl. Acad. Sci. U.S.A. 88, 2451-2455. doi: 10.1073/pnas.88.6.2451

Colpitts, C. C., Lupberger, J., Doerig, C., and Baumert, T. F. (2015). Host cell kinases and the hepatitis C virus life cycle. Biochim. Biophys. Acta 1854, 1657-1662. doi: 10.1016/j.bbapap.2015.04.011

Cui, M., You, L., Ren, X., Zhao, W., Liao, Q., and Zhao, Y. (2016). Long noncoding RNA PVT1 and cancer. Biochem. Biophys. Res. Commun. 471, 10-14. doi: 10.1016/j.bbrc.2015.12.101

Dabo, S., and Meurs, E. F. (2012). dsRNA-dependent protein kinase PKR and its role in stress, signaling and HCV infection. Viruses 4, 2598-2635. doi: 10.3390/ v4112598

Dafa-Berger, A., Kuzmina, A., Fassler, M., Yitzhak-Asraf, H., Shemer-Avni, Y., and Taube, R. (2012). Modulation of hepatitis C virus release by the interferoninduced protein BST-2/tetherin. Virology 428, 98-111. doi: 10.1016/j.virol.2012. 03.011

Daw, M. A., El-Bouzedi, A. A., Ahmed, M. O., Dau, A. A., Agnan, M. M., and Drah, A. M. (2016). Geographic integration of hepatitis $C$ virus: a global threat. World J. Virol. 5, 170-182. doi: 10.5501/wjv.v5.i4.170

Delang, L., Paeshuyse, J., and Neyts, J. (2012). The role of phosphatidylinositol 4-kinases and phosphatidylinositol 4-phosphate during viral replication. Biochem. Pharmacol. 84, 1400-1408. doi: 10.1016/j.bcp.2012.07.034

Djebali, S., Davis, C. A., Merkel, A., Dobin, A., Lassmann, T., Mortazavi, A., et al. (2012). Landscape of transcription in human cells. Nature 489, 101-108. doi: $10.1038 /$ nature 11233

Dreux, M., Garaigorta, U., Boyd, B., Décembre, E., Chung, J., Whitten-Bauer, C., et al. (2012). Short-range exosomal transfer of viral RNA from infected cells to plasmacytoid dendritic cells triggers innate immunity. Cell Host Microbe 12, 558-570. doi: 10.1016/j.chom.2012.08.010

Duong, F. H. T., Filipowicz, M., Tripodi, M., La Monica, N., and Heim, M. H. (2004). Hepatitis $C$ virus inhibits interferon signaling through up-regulation of protein phosphatase 2A. Gastroenterology 126, 263-277. doi: 10.1053/j.gastro. 2003.10.076

Fortes, P., and Morris, K. V. (2016). Long noncoding RNAs in viral infections. Virus Res. 212, 1-11. doi: 10.1016/j.virusres.2015.10.002

Foy, E., Li, K., Sumpter, R., Loo, Y.-M., Johnson, C. L., Wang, C., et al. (2005). Control of antiviral defenses through hepatitis $\mathrm{C}$ virus disruption of retinoic acid-inducible gene-I signaling. Proc. Natl. Acad. Sci. U.S.A. 102, 2986-2991. doi: $10.1073 /$ pnas.0408707102 
Fu, N., Zhao, S.-X., Kong, L.-B., Du, J.-H., Ren, W.-G., Han, F., et al. (2017). LncRNA-ATB/microRNA-200a/ $\beta$-catenin regulatory axis involved in the progression of HCV-related hepatic fibrosis. Gene 618, 1-7. doi: 10.1016/ j.gene.2017.03.008

Fukuhara, T., Ono, C., Puig-Basagoiti, F., and Matsuura, Y. (2015). Roles of lipoproteins and apolipoproteins in particle formation of hepatitis $\mathrm{C}$ virus. Trends Microbiol. 23, 618-629. doi: 10.1016/j.tim.2015.07.007

Fullam, A., and Schröder, M. (2013). DExD/H-box RNA helicases as mediators of anti-viral innate immunity and essential host factors for viral replication. Biochim. Biophys. Acta 1829, 854-865. doi: 10.1016/j.bbagrm.2013.03.012

Gack, M. U., Shin, Y. C., Joo, C.-H., Urano, T., Liang, C., Sun, L., et al. (2007). TRIM25 RING-finger E3 ubiquitin ligase is essential for RIG-I-mediated antiviral activity. Nature 446, 916-920. doi: 10.1038/nature05732

Gago-Zachert, S. (2016). Viroids, infectious long non-coding RNAs with autonomous replication. Virus Res. 212, 12-24. doi: 10.1016/j.virusres.2015. 08.018

Garaigorta, U., and Chisari, F. V. (2009). Hepatitis C virus blocks interferon effector function by inducing protein kinase $\mathrm{R}$ phosphorylation. Cell Host Microbe 6, 513-522. doi: 10.1016/j.chom.2009.11.004

Garitano-Trojaola, A., Agirre, X., Prosper, F., and Fortes, P. (2013). Long noncoding RNAs in haematological malignancies. Int. J. Mol. Sci. 14, 15386-15422. doi: 10.3390/ijms140815386

Gastaminza, P., Dryden, K. A., Boyd, B., Wood, M. R., Law, M., Yeager, M., et al. (2010). Ultrastructural and biophysical characterization of hepatitis C virus particles produced in cell culture. J. Virol. 84, 10999-11009. doi: 10.1128/JVI. 00526- 10

Ge, D., Fellay, J., Thompson, A. J., Simon, J. S., Shianna, K. V., Urban, T. J., et al. (2009). Genetic variation in IL28B predicts hepatitis C treatment-induced viral clearance. Nature 461, 399-401. doi: 10.1038/nature08309

Gerresheim, G. K., Nadia Dünnes, B., Anika Nieder-Röhrmann, B., Shalamova, L. A., Höner zu Siederdissen, C., Manja Marz, B., et al. (2017). microRNA-122 target sites in the hepatitis C virus RNA NS5B coding region and $3^{\prime}$ untranslated region: function in replication and influence of RNA secondary structure. Cell. Mol. Life Sci. 74, 747-760. doi: 10.1007/s00018-016-2377-9

Ghany, M. G., Strader, D. B., Thomas, D. L., and Seeff, L. B. (2009). Diagnosis, management, and treatment of hepatitis C: an update. Hepatology 49, 1335-1374. doi: 10.1002/hep.22759

Gokhale, N. S., Vazquez, C., and Horner, S. M. (2014). Hepatitis C virus. Strategies to evade antiviral responses. Future Virol. 9, 1061-1075. doi: 10.2217/fvl.14.89

Gower, E., Estes, C., Blach, S., Razavi-Shearer, K., and Razavi, H. (2014). Global epidemiology and genotype distribution of the hepatitis $\mathrm{C}$ virus infection. J. Hepatol. 61, S45-S57. doi: 10.1016/j.jhep.2014.07.027

Graham, M., Adams, J. M., and Cory, S. (1985). Murine T lymphomas with retroviral inserts in the chromosomal 15 locus for plasmacytoma variant translocations. Nature 314, 740-743. doi: 10.1038/314740a0

Grassi, G., Di Caprio, G., Fimia, G. M., Ippolito, G., Tripodi, M., and Alonzi, T. (2016). Hepatitis C virus relies on lipoproteins for its life cycle. World J. Gastroenterol. 22, 1953-1965. doi: 10.3748/wjg.v22.i6.1953

Guttman, M., Amit, I., Garber, M., French, C., Lin, M. F., Feldser, D., et al. (2009). Chromatin signature reveals over a thousand highly conserved large non-coding RNAs in mammals. Nature 458, 223-227. doi: 10.1038/nature 07672

Han, Q., Manna, D., Belton, K., Cole, R., and Konan, K. V. (2013). Modulation of hepatitis $\mathrm{C}$ virus genome encapsidation by nonstructural protein 4 B. J. Virol. 87, 7409-7422. doi: 10.1128/JVI.03523-12

Harries, L. W. (2012). Long non-coding RNAs and human disease. Biochem. Soc. Trans. 40, 902-906. doi: 10.1042/BST20120020

Hattlmann, C. J., Kelly, J. N., and Barr, S. D. (2012). TRIM22: a diverse and dynamic antiviral protein. Mol. Biol. Int. 2012:153415. doi: 10.1155/2012/153415

Heintzman, N. D., Stuart, R. K., Hon, G., Fu, Y., Ching, C. W., Hawkins, R. D., et al. (2007). Distinct and predictive chromatin signatures of transcriptional promoters and enhancers in the human genome. Nat. Genet. 39, 311-318. doi: $10.1038 /$ ng 1966

Helbig, K. J., Eyre, N. S., Yip, E., Narayana, S., Li, K., Fiches, G., et al. (2011). The antiviral protein viperin inhibits hepatitis $C$ virus replication via interaction with nonstructural protein 5A. Hepatology 54, 1506-1517. doi: 10.1002/hep. 24542
Helbig, K. J., Lau, D. T.-Y., Semendric, L., Harley, H. A. J., and Beard, M. R. (2005). Analysis of ISG expression in chronic hepatitis $\mathrm{C}$ identifies viperin as a potential antiviral effector. Hepatology 42, 702-710. doi: 10.1002/hep.20844

Hemmi, H., Takeuchi, O., Sato, S., Yamamoto, M., Kaisho, T., Sanjo, H., et al. (2004). The roles of two IkappaB kinase-related kinases in lipopolysaccharide and double stranded RNA signaling and viral infection. J. Exp. Med. 199, 1641-1650. doi: 10.1084/jem.20040520

Henke, J. I., Goergen, D., Zheng, J., Song, Y., Schüttler, C. G., Fehr, C., et al. (2008). microRNA-122 stimulates translation of hepatitis C virus RNA. EMBO J. 27, 3300-3310. doi: 10.1038/emboj.2008.244

Hertzog, P. J., and Williams, B. R. (2013). Fine tuning type I interferon responses. Cytokine Growth Factor Rev. 24, 217-225. doi: 10.1016/j.cytogfr.2013.04.002

Higgs, M. R., Lerat, H., and Pawlotsky, J. M. (2013). Hepatitis C virus-induced activation of beta-catenin promotes c-Myc expression and a cascade of procarcinogenetic events. Oncogene 32, 4683-4693. doi: 10.1038/onc.2012.484

Horner, S. M., and Gale, M. (2013). Regulation of hepatic innate immunity by hepatitis C virus. Nat. Med. 19, 879-888. doi: 10.1038/nm.3253

Hu, Y., Zhou, W., Ren, J., Dong, L., Wang, Y., Jin, S., et al. (2016). Annotating the function of the human genome with gene ontology and disease ontology. Biomed Res. Int. 2016:4130861. doi: 10.1155/2016/4130861

Huang, H., Sun, F., Owen, D. M., Li, W., Chen, Y., Gale, M., et al. (2007). Hepatitis $\mathrm{C}$ virus production by human hepatocytes dependent on assembly and secretion of very low-density lipoproteins. Proc. Natl. Acad. Sci. U.S.A. 104, 5848-5853. doi: 10.1073/pnas.0700760104

Huang, J. F., Guo, Y. J., Zhao, C. X., Yuan, S. X., Wang, Y., Tang, G. N., et al. (2013). Hepatitis $B$ virus $X$ protein $(\mathrm{HBx})$-related long noncoding RNA (lncRNA) down-regulated expression by $\mathrm{HBx}$ (Dreh) inhibits hepatocellular carcinoma metastasis by targeting the intermediate filament protein vimentin. Hepatology 57, 1882-1892. doi: 10.1002/hep.26195

Huang, M., Hou, J., Wang, Y., Xie, M., Wei, C., Nie, F., et al. (2017). Long noncoding RNA LINC00673 is activated by SP1 and exerts oncogenic properties by interacting with LSD1 and EZH2 in gastric cancer. Mol. Ther. 25, 1014-1026. doi: 10.1016/j.ymthe.2017.01.017

Imam, H., Bano, A. S., Patel, P., Holla, P., and Jameel, S. (2015). The lncRNA NRON modulates HIV-1 replication in a NFAT-dependent manner and is differentially regulated by early and late viral proteins. Sci. Rep. 5:8639. doi: 10.1038/srep08639

Imran, M., Waheed, Y., Manzoor, S., Bilal, M., Ashraf, W., Ali, M., et al. (2012). Interaction of Hepatitis $\mathrm{C}$ virus proteins with pattern recognition receptors. Virol. J. 9:126. doi: 10.1186/1743-422X-9-126

Israelow, B., Mullokandov, G., Agudo, J., Sourisseau, M., Bashir, A., Maldonado, A. Y., et al. (2014). Hepatitis $C$ virus genetics affects miR-122 requirements and response to miR-122 inhibitors. Nat. Commun. 5:5408. doi: 10.1038/ ncomms6408

Itsui, Y., Sakamoto, N., Kakinuma, S., Nakagawa, M., Sekine-Osajima, Y., TasakaFujita, M., et al. (2009). Antiviral effects of the interferon-induced protein guanylate binding protein 1 and its interaction with the hepatitis C virus NS5B protein. Hepatology 50, 1727-1737. doi: 10.1002/hep.23195

Ivanov, A. V., Smirnova, O. A., Ivanova, O. N., Masalova, O. V., Kochetkov, S. N., and Isaguliants, M. G. (2011). Hepatitis C virus proteins activate NRF2/ARE pathway by distinct ROS-dependent and independent mechanisms in HUH7 cells. PLOS ONE 6:e24957. doi: 10.1371/journal.pone.0024957

Ivashkiv, L. B., and Donlin, L. T. (2014). Regulation of type I interferon responses. Nat. Rev. 14, 36-49. doi: 10.1038/nri3581

Iyer, M. K., Niknafs, Y. S., Malik, R., Singhal, U., Sahu, A., Hosono, Y., et al. (2015). The landscape of long noncoding RNAs in the human transcriptome. Nat. Genet. 47, 199-208. doi: 10.1038/ng.3192

Janssen, H. L., Reesink, H. W., Lawitz, E. J., Zeuzem, S., Rodriguez-Torres, M., Patel, K., et al. (2013). Treatment of HCV infection by targeting microRNA. N. Engl. J. Med. 368, 1685-1694. doi: 10.1056/NEJMoa1209026

Jirasko, V., Montserret, R., Lee, J. Y., Gouttenoire, J., Moradpour, D., Penin, F., et al. (2010). Structural and functional studies of nonstructural protein 2 of the hepatitis $\mathrm{C}$ virus reveal its key role as organizer of virion assembly. PLOS Pathog. 6:e1001233. doi: 10.1371/journal.ppat.1001233

Jopling, C. L., Yi, M., Lancaster, A. M., Lemon, S. M., and Sarnow, P. (2005). Modulation of hepatitis C virus RNA abundance by a liver-specific MicroRNA. Science 309, 1577-1581. doi: 10.1126/science.1113329 
Kambara, H., Gunawardane, L., Zebrowski, E., Kostadinova, L., Jobava, R., Hatzoglou, M., et al. (2015). Regulation of Interferon-stimulated gene BST2 by a lncRNA transcribed from a shared bidirectional promoter. Front. Immunol. 5:676. doi: 10.3389/fimmu.2014.00676

Kambara, H., Niazi, F., Kostadinova, L., Moonka, D. K., Siegel, C. T., Post, A. B., et al. (2014). Negative regulation of the interferon response by an interferon-induced long non-coding RNA. Nucleic Acids Res. 42, 10668-10680. doi: 10.1093/nar/gku713

Kamel, M. M., Matboli, M., Sallam, M., Montasser, I. F., Saad, A. S., and El-Tawdi, A. H. F. (2016). Investigation of long noncoding RNAs expression profile as potential serum biomarkers in patients with hepatocellular carcinoma. Transl. Res. 168, 134-145. doi: 10.1016/j.trsl.2015.10.002

Kan, H., Imamura, M., Kawakami, Y., Daijo, K., Teraoka, Y., Honda, F., et al. (2017). Emergence of drug resistance-associated variants and changes in serum lipid profiles in sofosbuvir plus ledipasvir-treated chronic hepatitis $\mathrm{C}$ patients. J. Med. Virol. 89, 1963-1972. doi: 10.1002/jmv.24885

Kanda, T., Steele, R., Ray, R., and Ray, R. B. (2008). Hepatitis C virus core protein augments androgen receptor-mediated signaling. J. Virol. 82, 11066-11072. doi: 10.1128/JVI.01300-08

Kertesz, M., Wan, Y., Mazor, E., Rinn, J. L., Nutter, R. C., Chang, H. Y., et al. (2010). Genome-wide measurement of RNA secondary structure in yeast. Nature 467, 103-107. doi: 10.1038/nature09322

Kim, M. J., Hwang, S. Y., Imaizumi, T., and Yoo, J. Y. (2008). Negative feedback regulation of RIG-I-mediated antiviral signaling by interferon-induced ISG15 conjugation. J. Virol. 82, 1474-1483. doi: 10.1128/JVI.01650-07

Kutay, H., Bai, S., Datta, J., Motiwala, T., Pogribny, I., Frankel, W., et al. (2006). Downregulation of miR-122 in the rodent and human hepatocellular carcinomas. J. Cell. Biochem. 99, 671-678. doi: 10.1002/jcb.20982

Lai, F., Orom, U. A., Cesaroni, M., Beringer, M., Taatjes, D. J., Blobel, G. A., et al. (2013). Activating RNAs associate with Mediator to enhance chromatin architecture and transcription. Nature 494, 497-501. doi: 10.1038/nature11884

Landis, H., Simon-Jödicke, A., Klöti, A., Di Paolo, C., Schnorr, J. J., SchneiderSchaulies, S., et al. (1998). Human MxA protein confers resistance to Semliki Forest virus and inhibits the amplification of a Semliki Forest virus-based replicon in the absence of viral structural proteins. J. Virol. 72, 1516-1522.

Lanini, S., Easterbrook, P. J., Zumla, A., and Ippolito, G. (2016). Hepatitis C: global epidemiology and strategies for control. Clin. Microbiol. Infect. 22, 833-838. doi: 10.1016/j.cmi.2016.07.035

Lau, C.-C., Sun, T., Ching, A. K. K., He, M., Li, J.-W., Wong, A. M., et al. (2014). Viral-human chimeric transcript predisposes risk to liver cancer development and progression. Cancer Cell 25, 335-349. doi: 10.1016/j.ccr.2014.01.030

Lazar, D. C., Morris, K. V., and Saayman, S. M. (2016). The emerging role of long non-coding RNAs in HIV infection. Virus Res. 212, 114-126. doi: 10.1016/j. virusres.2015.07.023

Lemon, S. M., Walker, C. J. A. M., and Yi, M. (2007). Hepatitis C Virus, 5th Edn, eds D. M. Knipe and P. M. Howley (Philadelphia, PA: Lippincott Williams \& Wilkins), 1253-1304.

Li, J., Han, L., Roebuck, P., Diao, L., Liu, L., Yuan, Y., et al. (2015). TANRIC: an interactive open platform to explore the function of lncRNAs in cancer. Cancer Res. 75, 3728-3737. doi: 10.1158/0008-5472.CAN-15-0273

Li, M., Wang, Q., Liu, S.-A., Zhang, J.-Q., Ju, W., Quan, M., et al. (2015). MicroRNA-185-5p mediates regulation of SREBP2 expression by hepatitis C virus core protein. World J. Gastroenterol. 21, 4517-4525. doi: 10.3748/wjg.v21. i15.4517

Li, J., Tian, H., Yang, J., and Gong, Z. (2016). Long noncoding RNAs regulate cell growth, proliferation, and apoptosis. DNA Cell Biol. 35, 459-470. doi: 10.1089/ dna.2015.3187

Li, Q., Sodroski, C., Lowey, B., Schweitzer, C. J., Cha, H., Zhang, F., et al. (2016). Hepatitis $\mathrm{C}$ virus depends on E-cadherin as an entry factor and regulates its expression in epithelial-to-mesenchymal transition. Proc. Natl. Acad. Sci. U.S.A. 113, 7620-7625. doi: 10.1073/pnas.1602701113

Li, Z.-Q., Gu, X.-Y., Hu, J.-X., Ping, Y., Li, H., Yan, J.-Y., et al. (2016). Hepatitis $\mathrm{C}$ virus core protein impairs metabolic disorder of liver cell via HOTAIR-Sirt1 signalling. Biosci. Rep. 36:e00336. doi: 10.1042/BSR20160088

Li, K., Li, N. L., Wei, D., Pfeffer, S. R., Fan, M., and Pfeffer, L. M. (2012). Activation of chemokine and inflammatory cytokine response in hepatitis $\mathrm{C}$ virus-infected hepatocytes depends on toll-like receptor 3 sensing of hepatitis $\mathrm{C}$ virus doublestranded RNA intermediates. Hepatology 55, 666-675. doi: 10.1002/hep.24763
Li, Q., Pène, V., Krishnamurthy, S., Cha, H., and Liang, T. J. (2013). Hepatitis C virus infection activates an innate pathway involving IKK- $\alpha$ in lipogenesis and viral assembly. Nat. Med. 19, 722-729. doi: 10.1038/nm.3190

Li, R., Pan, Y., Shi, D.-D., Zhang, Y., and Zhang, J. (2013). PIAS1 negatively modulates virus triggered type I IFN signaling by blocking the DNA binding activity of IRF3. Antiviral Res. 100, 546-554. doi: 10.1016/j.antiviral.2013.09.001

Li, X., Wu, Z., Fu, X., and Han, W. (2013). Long noncoding RNAs: insights from biological features and functions to diseases. Med. Res. Rev. 33, 517-553. doi: 10.1002/med.21254

Li, Y., Masaki, T., Yamane, D., McGivern, D. R., and Lemon, S. M. (2013). Competing and noncompeting activities of miR-122 and the 5' exonuclease Xrn1 in regulation of hepatitis $\mathrm{C}$ virus replication. Proc. Natl. Acad. Sci. U.S.A. 110, 1881-1886. doi: 10.1073/pnas.1213515110

Li, X.-D., Sun, L., Seth, R. B., Pineda, G., and Chen, Z. J. (2005). Hepatitis C virus protease NS3/4A cleaves mitochondrial antiviral signaling protein off the mitochondria to evade innate immunity. Proc. Natl. Acad. Sci. U.S.A. 102, 17717-17722. doi: 10.1073/pnas.0508531102

Liu, B., Liao, J., Rao, X., Kushner, S. A., Chung, C. D., Chang, D. D., et al. (1998). Inhibition of Stat1-mediated gene activation by PIAS1. Proc. Natl. Acad. Sci. U.S.A. 95, 10626-10631. doi: 10.1073/pnas.95.18.10626

Liu, H. M., Loo, Y.-M., Horner, S. M., Zornetzer, G. A., Katze, M. G., Gale, M., et al. (2012). The mitochondrial targeting chaperone $14-3-3 \varepsilon$ regulates a RIG-I translocon that mediates membrane association and innate antiviral immunity. Cell Host Microbe 11, 528-537. doi: 10.1016/j.chom.2012.04.006

Lohmann, V. (2013). Hepatitis C virus RNA replication. Curr. Top. Microbiol. Immunol. 369, 167-198. doi: 10.1007/978-3-642-27340-7_7

Lonsdale, J., Thomas, J., Salvatore, M., Phillips, R., Lo, E., Shad, S., et al. (2013). The genotype-tissue expression (GTEx) project. Nat. Genet. 45, 580-585. doi: 10.1038/ng.2653

Luna, J., Scheel, T. H., Danino, T., Shaw, K., Mele, A., Fak, J., et al. (2015). Hepatitis C virus RNA functionally sequesters miR-122. Cell 160, 1099-1110. doi: 10.1016/j.cell.2015.02.025

Ma, C., Wu, G., Zhu, Q., Liu, H., Yao, Y., Yuan, D., et al. (2017). Long intergenic noncoding RNA 00673 promotes non-small-cell lung cancer metastasis by binding with EZH2 and causing epigenetic silencing of HOXA5. Oncotarget 8, 32696-32705. doi: 10.18632/oncotarget.16158

Machida, K., Cheng, K. T.-H., Lai, C.-K., Jeng, K.-S., Sung, V. M.-H., and Lai, M. M. C. (2006). Hepatitis C virus triggers mitochondrial permeability transition with production of reactive oxygen species, leading to DNA damage and STAT3 activation. J. Virol. 80, 7199-7207. doi: 10.1128/JVI.00321-06

Malakhova, O. A., Kim, K. I., Luo, J.-K., Zou, W., Kumar, K. G. S., Fuchs, S. Y., et al. (2006). UBP43 is a novel regulator of interferon signaling independent of its ISG15 isopeptidase activity. EMBO J. 25, 2358-2367. doi: 10.1038/sj.emboj. 7601149

Malireddi, R. K. S., and Kanneganti, T.-D. (2013). Role of type I interferons in inflammasome activation, cell death, and disease during microbial infection. Front. Cell. Infect. Microbiol. 3:77. doi: 10.3389/fcimb.2013.00077

Mancone, C., Montaldo, C., Santangelo, L., Di Giacomo, C., Costa, V., Amicone, L., et al. (2012). Ferritin heavy chain is the host factor responsible for HCV-induced inhibition of apoB-100 production and is required for efficient viral infection. J. Proteome Res. 11, 2786-2797. doi: 10.1021/pr201128s

Manns, M. P., Buti, M., Gane, E., Pawlotsky, J.-M., Razavi, H., Terrault, N., et al. (2017). Hepatitis C virus infection. Nat. Rev. Dis. Primers 3:17006. doi: 10.1038/ nrdp.2017.6

Mao, Y. S., Sunwoo, H., Zhang, B., and Spector, D. L. (2011). Direct visualization of the co-transcriptional assembly of a nuclear body by noncoding RNAs. Nat. Cell Biol. 13, 95-101. doi: 10.1038/ncb2140

Marascio, N., Torti, C., Liberto, M., and Focà, A. (2014). Update on different aspects of HCV variability: focus on NS5B polymerase. BMC Infect. Dis. 14(Suppl. 5):S1. doi: 10.1186/1471-2334-14-S5-S1

Maris, J. M., Mosse, Y. P., Bradfield, J. P., Hou, C., Monni, S., Scott, R. H., et al. (2008). Chromosome $6 \mathrm{p} 22$ locus associated with clinically aggressive neuroblastoma. N. Engl. J. Med. 358, 2585-2593. doi: 10.1056/NEJMoa0708698

Marques, A. C., and Ponting, C. P. (2014). Intergenic lncRNAs and the evolution of gene expression. Curr. Opin. Genet. Dev. 27, 48-53. doi: 10.1016/j.gde.2014. 03.009

McFarland, A. P., Horner, S. M., Jarret, A., Joslyn, R. C., Bindewald, E., Shapiro, B. A., et al. (2013). The favorable IFNL3 genotype escapes mRNA decay 
mediated by AU-rich elements and hepatitis C virus-induced microRNAs. Nat. Immunol. 15, 72-79. doi: 10.1038/ni.2758

Melo, C. A., Drost, J., Wijchers, P. J., van de Werken, H., de Wit, E., Oude Vrielink, J. A., et al. (2013). eRNAs are required for p53-dependent enhancer activity and gene transcription. Mol. Cell 49, 524-535. doi: 10.1016/j.molcel.2012.11.021

Meylan, E., Curran, J., Hofmann, K., Moradpour, D., Binder, M., Bartenschlager, R., et al. (2005). Cardif is an adaptor protein in the RIG-I antiviral pathway and is targeted by hepatitis C virus. Nature 437, 1167-1172. doi: 10.1038/nature04193

Miao, Z., Xie, Z., Miao, J., Ran, J., Feng, Y., and Xia, X. (2017). Regulated entry of hepatitis C virus into hepatocytes. Viruses 9:100. doi: 10.3390/v9050100

Misawa, A., Takayama, K.-I., Urano, T., and Inoue, S. (2016). Androgen-induced long noncoding RNA (lncRNA) SOCS2-AS1 promotes cell growth and inhibits apoptosis in prostate cancer cells. J. Biol. Chem. 291, 17861-17880. doi: 10.1074/ jbc.M116.718536

Miura, K., Taura, K., Kodama, Y., Schnabl, B., and Brenner, D. A. (2008). Hepatitis C virus-induced oxidative stress suppresses hepcidin expression through increased histone deacetylase activity. Hepatology 48, 1420-1429. doi: 10.1002/hep.22486

Moon, S. L., Blackinton, J. G., Anderson, J. R., Dozier, M. K., Dodd, B. J. T., Keene, J. D., et al. (2015). XRN1 stalling in the 5' UTR of Hepatitis C virus and Bovine Viral Diarrhea virus is associated with dysregulated host mRNA stability. PLOS Pathog. 11:e1004708. doi: 10.1371/journal.ppat.1004708

Moradpour, D., and Penin, F. (2013). Hepatitis C virus proteins: from structure to function. Curr. Top. Microbiol. Immunol. 369, 113-142. doi: 10.1007/978-3642-27340-7_5

Moyo, B., Nicholson, S. A., and Arbuthnot, P. B. (2016). The role of long noncoding RNAs in hepatitis B virus-related hepatocellular carcinoma. Virus Res. 212, 103-113. doi: 10.1016/j.virusres.2015.07.025

Mukherjee, A., Di Bisceglie, A. M., and Ray, R. B. (2015). Hepatitis C virusmediated enhancement of microRNA miR-373 impairs the JAK/STAT signaling pathway. J. Virol. 89, 3356-3365. doi: 10.1128/JVI.03085-14

Murakami, Y., Toyoda, H., Tanaka, M., Kuroda, M., Harada, Y., Matsuda, F., et al. (2011). The progression of liver fibrosis is related with overexpression of the miR-199 and 200 families. PLOS ONE 6:e16081. doi: 10.1371/journal.pone. 0016081

Nakai, M., Oshiumi, H., Funami, K., Okamoto, M., Matsumoto, M., Seya, T., et al. (2015). Interferon (IFN) and cellular immune response evoked in RNA-pattern sensing during infection with hepatitis C virus (HCV). Sensors 15, 27160-27173. doi: 10.3390/s151027160

Narayana, S. K., Helbig, K. J., McCartney, E. M., Eyre, N. S., Bull, R. A., Eltahla, A., et al. (2015). The interferon-induced transmembrane proteins, IFITM1, IFITM2, and IFITM3 inhibit hepatitis C virus entry. J. Biol. Chem. 290, 25946-25959. doi: 10.1074/jbc.M115.657346

Nasimuzzaman, M., Waris, G., Mikolon, D., Stupack, D. G., and Siddiqui, A. (2007). Hepatitis C virus stabilizes hypoxia-inducible factor 1alpha and stimulates the synthesis of vascular endothelial growth factor. J. Virol. 81, 10249-10257. doi: 10.1128/JVI.00763-07

Neil, S. J., Zang, T., and Bieniasz, P. D. (2008). Tetherin inhibits retrovirus release and is antagonized by HIV-1 Vpu. Nature 451, 425-430. doi: 10.1038/ nature 06553

Nishina, S., Hino, K., Korenaga, M., Vecchi, C., Pietrangelo, A., Mizukami, Y., et al. (2008). Hepatitis C virus-induced reactive oxygen species raise hepatic iron level in mice by reducing hepcidin transcription. Gastroenterology 134, 226-238. doi: 10.1053/j.gastro.2007.10.011

Ooi, Y. S., Dube, M., and Kielian, M. (2015). BST2/tetherin inhibition of alphavirus exit. Viruses 7, 2147-2167. doi: 10.3390/v7042147

Orom, U. A., Derrien, T., Beringer, M., Gumireddy, K., Gardini, A., Bussotti, G., et al. (2010). Long noncoding RNAs with enhancer-like function in human cells. Cell 143, 46-58. doi: 10.1016/j.cell.2010.09.001

Oshiumi, H., Funami, K., Aly, H. H., Matsumoto, M., and Seya, T. (2013a). Multistep regulation of interferon induction by hepatitis $\mathrm{C}$ virus. Arch. Immunol. Ther. Exp. 61, 127-138. doi: 10.1007/s00005-012-0214-x

Oshiumi, H., Miyashita, M., Matsumoto, M., and Seya, T. (2013b). A distinct role of riplet-mediated K63-linked polyubiquitination of the RIG-I repressor domain in human antiviral innate immune responses. PLOS Pathog. 9:e1003533. doi: 10.1371/journal.ppat.1003533

Oshiumi, H., Miyashita, M., Inoue, N., Okabe, M., Matsumoto, M., and Seya, T. (2010). The ubiquitin ligase riplet is essential for RIG-I-dependent innate immune responses to RNA virus infection. Cell Host Microbe 8, 496-509. doi: 10.1016/j.chom.2010.11.008

Ouyang, J., Hu, J., and Chen, J.-L. (2016). IncRNAs regulate the innate immune response to viral infection. Wiley Interdiscip. Rev. RNA 7, 129-143. doi: 10.1002/ wrna. 1321

Ouyang, J., Zhu, X., Chen, Y., Wei, H., Chen, Q., Chi, X., et al. (2014). NRAV, a long noncoding RNA, modulates antiviral responses through suppression of interferon-stimulated gene transcription. Cell Host Microbe 16, 616-626. doi: 10.1016/j.chom.2014.10.001

Pan, X. B., Qu, X. W., Jiang, D., Zhao, X. L., Han, J. C., and Wei, L. (2013). BST2/Tetherin inhibits hepatitis $\mathrm{C}$ virus production in human hepatoma cells. Antiviral Res. 98, 54-60. doi: 10.1016/j.antiviral.2013.01.009

Panda, A. C., Grammatikakis, I., Kim, K. M., De, S., Martindale, J. L., Munk, R., et al. (2017). Identification of senescence-associated circular RNAs (SAC-RNAs) reveals senescence suppressor CircPVT1. Nucleic Acids Res. 45, 4021-4035. doi: 10.1093/nar/gkw1201

Pène, V., Li, Q., Sodroski, C., Hsu, C.-S., and Liang, T. J. (2015). Dynamic interaction of stress granules, DDX $3 \mathrm{X}$, and IKK- $\alpha$ mediates multiple functions in hepatitis C virus infection. J. Virol. 89, 5462-5477. doi: 10.1128/JVI.03 197-14

Perales, C., Quer, J., Gregori, J., Esteban, J., and Domingo, E. (2015). Resistance of hepatitis C virus to inhibitors: complexity and clinical implications. Viruses 7, 5746-5766. doi: 10.3390/v7112902

Perez-Caballero, D., Zang, T., Ebrahimi, A., McNatt, M. W., Gregory, D. A., Johnson, M. C., et al. (2009). Tetherin inhibits HIV-1 release by directly tethering virions to cells. Cell 139, 499-511. doi: 10.1016/j.cell.2009.08.039

Perreira, J. M., Chin, C. R., Feeley, E. M., and Brass, A. L. (2013). IFITMs restrict the replication of multiple pathogenic viruses. J. Mol. Biol. 425, 4937-4955. doi: 10.1016/j.jmb.2013.09.024

Poordad, F., and Khungar, V. (2011). Emerging therapeutic options in hepatitis C virus infection. Am. J. Manag. Care 17(Suppl. 4), S123-S130.

Prensner, J. R., and Chinnaiyan, A. M. (2011). The emergence of lncRNAs in cancer biology. Cancer Discov. 1, 391-407. doi: 10.1158/2159-8290.CD-11-0209

Raj, V. S., Hundie, G. B., Schürch, A. C., Smits, S. L., Pas, S. D., Le Pogam, S., et al. (2017). Identification of HCV resistant variants against direct acting antivirals in plasma and liver of treatment naïve patients. Sci. Rep. 7:4688. doi: 10.1038/s41598-017-04931-y

Raychoudhuri, A., Shrivastava, S., Steele, R., Kim, H., Ray, R., and Ray, R. B. (2011). ISG56 and IFITM1 proteins inhibit hepatitis C virus replication. J. Virol. 85, 12881-12889. doi: 10.1128/JVI.05633-11

Ríos-Marco, P., Romero-López, C., and Berzal-Herranz, A. (2016). The cis-acting replication element of the Hepatitis $\mathrm{C}$ virus genome recruits host factors that influence viral replication and translation. Sci. Rep. 6:25729. doi: 10.1038/ srep25729

Romero-Lopez, C., and Berzal-Herranz, A. (2009). A long-range RNA-RNA interaction between the $5^{\prime}$ and $3^{\prime}$ ends of the HCV genome. RNA 15, 1740-1752. doi: 10.1261/rna.1680809

Rose, D., and Stadler, P. F. (2011). Molecular evolution of the non-coding eosinophil granule ontogeny transcript. Front. Genet. 2:69. doi: 10.3389/fgene. 2011.00069

Rosnoblet, C., Fritzinger, B., Legrand, D., Launay, H., Wieruszeski, J.-M., Lippens, G., et al. (2012). Hepatitis C virus NS5B and host cyclophilin A share a common binding site on NS5A. J. Biol. Chem. 287, 44249-44260. doi: 10.1074/ jbc.M112.392209

Ross-Thriepland, D., Amako, Y., and Harris, M. (2013). The C terminus of NS5A domain II is a key determinant of hepatitis $\mathrm{C}$ virus genome replication, but is not required for virion assembly and release. J. Gen. Virol. 94, 1009-1018. doi: 10.1099/vir.0.050633-0

Russell, M. R., Penikis, A., Oldridge, D. A., Alvarez-Dominguez, J. R., McDaniel, L., Diamond, M., et al. (2015). CASC15-S is a tumor suppressor lncRNA at the 6p22 neuroblastoma susceptibility locus. Cancer Res. 75, 3155-3166. doi: 10.1158/0008-5472.CAN-14-3613

Sagan, S. M., Chahal, J., and Sarnow, P. (2015). cis-Acting RNA elements in the hepatitis C virus RNA genome. Virus Res. 206, 90-98. doi: 10.1016/j.virusres. 2014.12.029

Saito, T., Owen, D. M., Jiang, F., Marcotrigiano, J., and Gale, M. (2008). Innate immunity induced by composition-dependent RIG-I recognition of hepatitis C virus RNA. Nature 454, 523-527. doi: 10.1038/nature07106 
Sarrazin, C., Hézode, C., Zeuzem, S., and Pawlotsky, J.-M. (2012). Antiviral strategies in hepatitis C virus infection. J. Hepatol. 56, S88-S100. doi: 10.1016/ S0168-8278(12)60010-5

Scheel, T. K., and Rice, C. M. (2013). Understanding the hepatitis C virus life cycle paves the way for highly effective therapies. Nat. Med. 19, 837-849. doi: $10.1038 / \mathrm{nm} .3248$

Schneider, W. M., Chevillotte, M. D., and Rice, C. M. (2014). Interferon-stimulated genes: a complex web of host defenses. Annu. Rev. Immunol. 32, 513-545. doi: 10.1146/annurev-immunol-032713-120231

Schoggins, J. W., and Rice, C. M. (2013). Innate immune responses to hepatitis C virus. Curr. Top. Microbiol. Immunol. 369, 219-242. doi: 10.1007/978-3-64227340-7_9

Schoggins, J. W., Wilson, S. J., Panis, M., Murphy, M. Y., Jones, C. T., Bieniasz, P., et al. (2011). A diverse range of gene products are effectors of the type I interferon antiviral response. Nature 472, 481-485. doi: 10.1038/nature09907

Schregel, V., Jacobi, S., Penin, F., and Tautz, N. (2009). Hepatitis C virus NS2 is a protease stimulated by cofactor domains in NS3. Proc. Natl. Acad. Sci. U.S.A. 106, 5342-5347. doi: 10.1073/pnas.0810950106

Sedano, C. D., and Sarnow, P. (2014). Hepatitis C virus subverts liver-specific miR122 to protect the viral genome from exoribonuclease Xrn2. Cell Host Microbe 16, 257-264. doi: 10.1016/j.chom.2014.07.006

Sharma, S., tenOever, B. R., Grandvaux, N., Zhou, G.-P., Lin, R., and Hiscott, J. (2003). Triggering the interferon antiviral response through an IKK-related pathway. Science 300, 1148-1151. doi: 10.1126/science.1081315

Sheridan, D. A., Neely, R. D. G., and Bassendine, M. F. (2013). Hepatitis C virus and lipids in the era of direct acting antivirals (DAAs). Clin. Res. Hepatol. Gastroenterol. 37, 10-16. doi: 10.1016/j.clinre.2012.07.002

Shi, G., Ando, T., Suzuki, R., Matsuda, M., Nakashima, K., Ito, M., et al. (2016). Involvement of the $3^{\prime}$ untranslated region in encapsidation of the hepatitis $\mathrm{C}$ virus. PLOS Pathog. 12:e1005441. doi: 10.1371/journal.ppat.1005441

Shi, X., Ma, C., Zhu, Q., Yuan, D., Sun, M., Gu, X., et al. (2016). Upregulation of long intergenic noncoding RNA 00673 promotes tumor proliferation via LSD1 interaction and repression of NCALD in non-small-cell lung cancer. Oncotarget 7, 25558-25575. doi: 10.18632/oncotarget.8338

Shi, X., Jiao, B., Chen, Y., Li, S., and Chen, L. (2017). MxA is a positive regulator of type I IFN signaling in HCV infection. J. Med. Virol. doi: 10.1002/jmv.24867 [Epub ahead of print].

Shimakami, T., Yamane, D., Welsch, C., Hensley, L., Jangra, R. K., and Lemon, S. M. (2012). Base pairing between hepatitis C virus RNA and MicroRNA 122 3' of its seed sequence is essential for genome stabilization and production of infectious virus. J. Virol. 86, 7372-7383. doi: 10.1128/JVI.00513-12

Shimura, H., and Masuta, C. (2016). Plant subviral RNAs as a long noncoding RNA (lncRNA): analogy with animal lncRNAs in host-virus interactions. Virus Res. 212, 25-29. doi: 10.1016/j.virusres.2015.06.016

Shirasaki, T., Honda, M., Shimakami, T., Horii, R., Yamashita, T., Sakai, Y., et al. (2013). MicroRNA-27a regulates lipid metabolism and inhibits hepatitis C virus replication in human hepatoma cells. J. Virol. 87, 5270-5286. doi: 10.1128/JVI. 03022-12

Singaravelu, R., Chen, R., Lyn, R. K., Jones, D. M., O’Hara, S., Rouleau, Y., et al. (2014a). Hepatitis C virus induced up-regulation of microRNA-27: a novel mechanism for hepatic steatosis. Hepatology 59, 98-108. doi: 10.1002/hep.26634

Singaravelu, R., Russell, R. S., Tyrrell, D. L., and Pezacki, J. P. (2014b). Hepatitis $\mathrm{C}$ virus and microRNAs: miRed in a host of possibilities. Curr. Opin. Virol. 7, 1-10. doi: 10.1016/j.coviro.2014.03.004

Spizzo, R., Almeida, M. I., Colombatti, A., and Calin, G. A. (2012). Long noncoding RNAs and cancer: a new frontier of translational research? Oncogene 31, 4577-4587. doi: 10.1038/onc.2011.621

Stone, A. E. L., Giugliano, S., Schnell, G., Cheng, L., Leahy, K. F., Golden-Mason, L., et al. (2013). Hepatitis $C$ virus pathogen associated molecular pattern (PAMP) triggers production of lambda-interferons by human plasmacytoid dendritic cells. PLOS Pathog. 9:e1003316. doi: 10.1371/journal.ppat.1003316

Sun, J., Rajsbaum, R., and Yi, M. (2015). Immune and non-immune responses to hepatitis C virus infection. World J. Gastroenterol. 21, 10739-10748. doi: 10.3748/wjg.v21.i38.10739

Syed, G. H., Khan, M., Yang, S., and Siddiqui, A. (2017). Hepatitis C virus lipoviroparticles assemble in the endoplasmic reticulum (ER) and bud off from the ER to the Golgi Compartment in COPII vesicles. J. Virol. 91:e00499-17. doi: 10.1128/JVI.00499-17
Takahashi, K., Asabe, S., Wieland, S., Garaigorta, U., Gastaminza, P., Isogawa, M., et al. (2010). Plasmacytoid dendritic cells sense hepatitis $C$ virus-infected cells, produce interferon, and inhibit infection. Proc. Natl. Acad. Sci. U.S.A. 107, 7431-7436. doi: 10.1073/pnas.1002301107

Targett-Adams, P., Boulant, S., Douglas, M. W., and McLauchlan, J. (2010). Lipid metabolism and HCV infection. Viruses 2, 1195-1217. doi: 10.3390/v2051195

Thibault, P. A., Huys, A., Amador-Cañizares, Y., Gailius, J. E., Pinel, D. E., and Wilson, J. A. (2015). Regulation of hepatitis $C$ virus genome replication by Xrn1 and microRNA-122 binding to individual sites in the $5^{\prime}$ untranslated region. J. Virol. 89, 6294-6311. doi: 10.1128/JVI.03631-14

Thomas, D. L., Thio, C. L., Martin, M. P., Qi, Y., Ge, D., O’Huigin, C., et al. (2009). Genetic variation in IL28B and spontaneous clearance of hepatitis C virus. Nature 461, 798-801. doi: 10.1038/nature08463

Thompson, M. R., Kaminski, J. J., Kurt-Jones, E. A., and Fitzgerald, K. A. (2011). Pattern recognition receptors and the innate immune response to viral infection. Viruses 3, 920-940. doi: 10.3390/v3060920

Timpe, J. M., Stamataki, Z., Jennings, A., Hu, K., Farquhar, M. J., Harris, H. J., et al. (2007). Hepatitis $C$ virus cell-cell transmission in hepatoma cells in the presence of neutralizing antibodies. Hepatology 47, 17-24. doi: 10.1002/hep. 21959

Tripathi, V., Ellis, J. D., Shen, Z., Song, D. Y., Pan, Q., Watt, A. T., et al. (2010). The nuclear-retained noncoding RNA MALAT1 regulates alternative splicing by modulating SR splicing factor phosphorylation. Mol. Cell 39, 925-938. doi: 10.1016/j.molcel.2010.08.011

Tseng, Y. Y., Moriarity, B. S., Gong, W., Akiyama, R., Tiwari, A., Kawakami, H., et al. (2014). PVT1 dependence in cancer with MYC copy-number increase. Nature 512, 82-86. doi: 10.1038/nature13311

Ulitsky, I., Shkumatava, A., Jan, C., Sive, H., and Bartel, D. (2011). Conserved function of lincRNAs in vertebrate embryonic development despite rapid sequence evolution. Cell 147, 1537-1550. doi: 10.1016/j.cell.2011.11.055

Wagner, L. A., Christensen, C. J., Dunn, D. M., Spangrude, G. J., Georgelas, A., Kelley, L., et al. (2007). EGO, a novel, noncoding RNA gene, regulates eosinophil granule protein transcript expression. Blood 109, 5191-5198. doi: 10.1182/blood-2006-06-027987

Wang, H., Guan, Z., He, K., Qian, J., Cao, J., and Teng, L. (2017). LncRNA UCA1 in anti-cancer drug resistance. Oncotarget 8, 64638-64650. doi: 10.18632/oncotarget.18344

Wang, P., Xue, Y., Han, Y., Lin, L., Wu, C., Xu, S., et al. (2014). The STAT3-binding long noncoding RNA lnc-DC controls human dendritic cell differentiation. Science 344, 310-313. doi: 10.1126/science.1251456

Wang, W.-B., Levy, D. E., and Lee, C.-K. (2011). STAT3 negatively regulates type I IFN-mediated antiviral response. J. Immunol. 187, 2578-2585. doi: 10.4049/ jimmunol.1004128

Wang, Z.-Q., Cai, Q., Hu, L., He, C.-Y., Li, J.-F., Quan, Z.-W., et al. (2017). Long noncoding RNA UCA1 induced by SP1 promotes cell proliferation via recruiting EZH2 and activating AKT pathway in gastric cancer. Cell Death Dis. 8:e2839. doi: $10.1038 /$ cddis. 2017.143

Wapinski, O., and Chang, H. Y. (2011). Long noncoding RNAs and human disease. Trends Cell Biol. 21, 354-361. doi: 10.1016/j.tcb.2011.04.001

Waris, G., Turkson, J., Hassanein, T., and Siddiqui, A. (2005). Hepatitis C virus (HCV) constitutively activates STAT-3 via oxidative stress: role of STAT-3 in HCV replication. J. Virol. 79, 1569-1580. doi: 10.1128/JVI.79.3.1569-1580.2005

Wilkins, C., Woodward, J., Lau, D. T., Barnes, A., Joyce, M., McFarlane, N., et al. (2013). IFITM1 is a tight junction protein that inhibits hepatitis C virus entry. Hepatology 57, 461-469. doi: 10.1002/hep.26066

Willingham, A. T., Orth, A. P., Batalov, S., Peters, E. C., Wen, B. G., Aza-Blanc, P., et al. (2005). A strategy for probing the function of noncoding RNAs finds a repressor of NFAT. Science 309, 1570-1573. doi: 10.1126/science.1115901

Wyles, D., Mangia, A., Cheng, W., Shafran, S., Schwabe, C., Ouyang, W., et al. (2017). Long-term persistence of HCV NS5A resistance-associated substitutions after treatment with the HCV NS5A inhibitor, ledipasvir, without sofosbuvir. Antivir. Ther. doi: 10.3851/IMP3181 [Epub ahead of print].

Xiang, Z., Qiao, L., Zhou, Y., Babiuk, L. A., and Liu, Q. (2010). Hepatitis C virus nonstructural protein-5A activates sterol regulatory element-binding protein1c through transcription factor Sp1. Biochem. Biophys. Res. Commun. 402, 549-553. doi: 10.1016/j.bbrc.2010.10.081

Xing, Y., Wen, X., Ding, X., Fan, J., Chai, P., Jia, R., et al. (2017). CANT1 lncRNA triggers efficient therapeutic efficacy by correcting aberrant lncing cascade in 
malignant uveal melanoma. Mol. Ther. 25, 1209-1221. doi: 10.1016/j.ymthe. 2017.02.016

Xiong, Y., Jia, M., Yuan, J., Zhang, C., Zhu, Y., Kuang, X., et al. (2015). STAT3regulated long non-coding RNAs lnc-7SK and lnc-IGF2-AS promote hepatitis C virus replication. Mol. Med. Rep. 12, 6738-6744. doi: 10.3892/mmr.2015.4278

Xu, Y., Martinez, P., Séron, K., Luo, G., Allain, F., Dubuisson, J., et al. (2015). Characterization of hepatitis $C$ virus interaction with heparan sulfate proteoglycans. J. Virol. 89, 3846-3858. doi: 10.1128/JVI.03647-14

Yan, H., Yang, Y., Zhang, L., Tang, G., Wang, Y., Xue, G., et al. (2015). Characterization of the genotype and integration patterns of hepatitis $B$ virus in early- and late-onset hepatocellular carcinoma. Hepatology 61, 1821-1831. doi: 10.1002/hep.27722

Yang, A., Lai, X., Wang, Y., Dai, H., You, Y., Liu, W., et al. (2017). Downregulation of LINC00673 promotes tumor proliferation via repression of HNF1A in human pancreatic ductal adenocarcinoma. Int. J. Clin. Exp. Med. 10, 4538-4546.

Yang, C., Zhao, X., Sun, D., Yang, L., Chong, C., Pan, Y., et al. (2016). Interferon alpha (IFN $\alpha$ )-induced TRIM22 interrupts HCV replication by ubiquitinating NS5A. Cell. Mol. Immunol. 13, 94-102. doi: 10.1038/cmi.2014.131

Yang, D.-R., and Zhu, H.-Z. (2015). Hepatitis C virus and antiviral innate immunity: Who wins at tug-of-war? World J. Gastroenterol. 21, 3786-3800. doi: 10.3748/wjg.v21.i13.3786

Yoon, J.-H., Abdelmohsen, K., Srikantan, S., Yang, X., Martindale, J., De, S., et al. (2012). LincRNA-p21 suppresses target mRNA translation. Mol. Cell 47, 648-655. doi: 10.1016/j.molcel.2012.06.027

Yoshida, T., Hanada, T., Tokuhisa, T., Kosai, K., Sata, M., Kohara, M., et al. (2002). Activation of STAT3 by the hepatitis C virus core protein leads to cellular transformation. J. Exp. Med. 196, 641-653. doi: 10.1084/jem.20012127

Yoshimura, A., Naka, T., and Kubo, M. (2007). SOCS proteins, cytokine signalling and immune regulation. Nat. Rev. Immunol. 7, 454-465. doi: 10.1038/nri2093

Yu, J., Liu, Y., Gong, Z., Zhang, S., Guo, C., Li, X., et al. (2017). Overexpression long non-coding RNA LINC00673 is associated with poor prognosis and promotes invasion and metastasis in tongue squamous cell carcinoma. Oncotarget 8 , 16621-16632. doi: 10.18632/oncotarget.14200

Yuan, J., Yang, F., Wang, F., Ma, J., Guo, Y., Tao, Q., et al. (2014). A long noncoding RNA activated by TGF- $\beta$ promotes the invasion-metastasis cascade in hepatocellular carcinoma. Cancer Cell 25, 666-681. doi: 10.1016/j.ccr.2014. 03.010

Zhang, H., Zhu, C., Zhao, Y., Li, M., Wu, L., Yang, X., et al. (2015). Long non-coding RNA expression profiles of hepatitis $\mathrm{C}$ virus-related dysplasia and hepatocellular carcinoma. Oncotarget 6, 43770-43778. doi: 10.18632/ oncotarget.6087

Zhang, Q., Matsuura, K., Kleiner, D. E., Zamboni, F., Alter, H. J., and Farci, P. (2016). Analysis of long noncoding RNA expression in hepatocellular carcinoma of different viral etiology. J. Transl. Med. 14, 328. doi: 10.1186/ s12967-016-1085-4

Zheng, J., Huang, X., Tan, W., Yu, D., Du, Z., Chang, J., et al. (2016). Pancreatic cancer risk variant in LINC00673 creates a miR-1231 binding site and interferes with PTPN11 degradation. Nat. Genet. 48, 747-757. doi: 10.1038/ng. 3568

Zhou, X., Michal, J. J., Zhang, L., Ding, B., Lunney, J. K., Liu, B., et al. (2013). Interferon induced IFIT family genes in host antiviral defense. Int. J. Biol. Sci. 9, 200-208. doi: 10.7150/ijbs.5613

Conflict of Interest Statement: The authors declare that the research was conducted in the absence of any commercial or financial relationships that could be construed as a potential conflict of interest.

Copyright (c) 2017 Barriocanal and Fortes. This is an open-access article distributed under the terms of the Creative Commons Attribution License (CC BY). The use, distribution or reproduction in other forums is permitted, provided the original author(s) or licensor are credited and that the original publication in this journal is cited, in accordance with accepted academic practice. No use, distribution or reproduction is permitted which does not comply with these terms. 